\title{
Analysis of microtomographic images in automatic defect localization and detection
}

\author{
Mariusz Marzec $^{1} \mathbb{D} \cdot$ Piotr Duda $^{1} \cdot$ Zygmunt Wróbel $^{1}$
}

Received: 19 August 2019 / Revised: 7 March 2020 / Accepted: 20 April 2020 / Published online: 27 May 2020

(C) The Author(s) 2020

\begin{abstract}
The paper presents a fast method of fully automatic localization and classification of defects in aluminium castings based on computed microtomography images. In the light of current research and based on available publications, where such analysis is made on the basis of images obtained from standard radiography (x-ray), this is a new approach which uses microtomographic images ( $\mu$-CT). In addition, the above-mentioned solutions most often analyze a pre-separated portion of an image, which requires the initial operator interference. The authors' own pre-processing methods, which allow to separate the element area and potential defect areas from $\mu$-CT images, and methods of extraction of selected features describing these areas have been proposed in the solution discussed here. A neural network trained using the Levenberg-Marquardt method with error backpropagation has been used as a classifier. The optimal network structure 20-4-1 and a set of 20 features describing the analysed areas have been determined as a result of performed tests. The applied solutions have provided $89 \%$ correct detection for any defect size and $96.73 \%$ for large defects, which is comparable to the results obtained from methods using x-ray images. This has confirmed that it is possible to use $\mu$-CT images in automatic defect localization in 3D. Thanks to this method, quantitative analysis of aluminium castings can be carried out without user interaction and fully automated.
\end{abstract}

Keywords Image analysis $\cdot$ Image processing $\cdot$ Neural networks $\cdot$ Segmentation $\cdot \mu$-CT microtomography $\cdot \mathrm{X}$-CT computed tomography $\cdot$ X-ray

\section{Introduction}

Tomographic images are good material for research in the field of image analysis. They are used in many fields of science and technology. In medical applications, tomographic images are used in the diagnosis and assessment of various diseases, such as concussion [1], visualization of internal organs [2], or bone imaging and examination [3]. Tomography is often used in museology to preserve works of art. It is very important in the preservation of wooden works of art [4]. In forensic science, tomography supports forensic-medical diagnostics, facilitating autopsy and making it more accurate [5]. Recently, computed tomography and microtomography have been extensively used in industry, to study production quality, in reverse engineering and technology [6-9]. Cur-

Mariusz Marzec

mariusz.marzec@us.edu.pl

1 Department of Computer Biomedical Systems, Institute of Computer Science, University of Silesia, ul. Bedzinska 39, 41-200 Sosnowiec, Poland rent examples of applications in medicine and industry have been discussed in [10]. The quality control process also uses other techniques of non-invasive assessment of aluminium castings: ultrasonic methods, eddy currents and pulsed thermography [11]. In the study presented in this paper, the authors focused on the analysis of tomographic images used in the quality control of aluminium castings. Standard quality assessment of this type of elements with the use of computed tomography is characterized by high labour intensity and the need for visual analysis of thousands of images (obtained as a result of reconstruction) for each element tested. There are problems related to the lack of repeatability in the visual analysis and relativity of the assessment process. It seems to be possible to improve and speed up such tasks by using computers. However, it requires specialized algorithms that will enable to perform these tasks automatically. The development of such algorithms may open up the potential for scalability of these solutions by using faster hardware or parallel calculations (each image can be analysed by another core). The paper presents the study aimed at developing a comprehensive algorithm for locating potential defect areas 
based on image processing methods, proposing a set of features describing the studied areas and building a classifier based on a neural network.

\section{Related work}

The issue of locating and assessing defects in aluminium castings is very important from the point of view of the quality control process. Its reliability and effectiveness have a big impact on safety in the subsequent use of construction elements created in this process. Current solutions and software packages allow for manual selection of defect areas, a semi-automatic process of calculating parameters describing the structure homogeneity. Depending on the needs, image binarization is performed manually for an experimentally defined brightness threshold. Such solutions are offered by practically all software packages intended for image analysis. However, the area of analysis is important in this case, because it must be related to the interior of the object. The user most often locates defect areas by viewing hundreds of images representing layers of the examined element, and then, using the basic image processing methods, performs quantitative analysis on the selected cutting planes of the object. An example of such a solution is the VGStudio package [12]-Fig. 12d (left). The user's task is to define operating parameters, e.g. binarization threshold and some additional information related to, for example, the number of pixels on the edge of the object that can be closed to mark the void as the internal porosity of the object. The application algorithm combines the porosities on individual layers and calculates their total volume and other features. In the end, a list of pores is obtained, along with the volume and location of the centre of gravity. Further analysis is carried out in accordance with the client's guidelines. The problem is porosity at the walls of objects and open porosity created as a result of other technological processes. Other software packages used in the laboratory to determine porosity are ImageJ [13] and CTAN [14], which offer similar capabilities in porosity analysis for flat images. Taking into consideration the high time-consuming nature of the activities described above, the need for user control and the potential for using computers in processing and analysis of such images, the authors have developed a comprehensive defect localization algorithm based on computed microtomography $(\mu-\mathrm{CT})$ images. The authors have analysed the available literature in terms of existing solutions and observed a large number of publications in this field, which proves the importance of the problem and the purposefulness of the research undertaken. Among the examples, there are attempts at locating defects and assessing them in a more or less automated way using specialized image analysis algorithms. The following are examples of solutions for visible light, based on standard x-ray and computed tomography (x-CT). In publication [15], the authors presented a method for the assessment and classification of surface defects in aluminium castings in visible light. A set of features was proposed (area, Feret elongation, compactness, roughness, length, breadth), which described the studied areas. A neural network was used as a classifier, and the studied set was divided into three subsets: $70 \%$ - training, $15 \%$ —validation, and $15 \%$ - test. The training process lasted until the network continued its improvement on the validation set. The test set yielded the following results: $90 \%$ for correct and $10 \%$ for incorrect detection. However, the authors do not mention the number of images in the studied set, which makes it difficult to objectively evaluate the results obtained. Importantly, due to the analysis of only the surface of castings, this method does not allow for the assessment of very significant defects formed inside the object. Another example [16] is the method of defect localization in aluminium or magnesium castings. Images obtained from $\mathrm{x}$-ray were initially subjected to normalization of size and scale and processed with a filter with an experimentally selected mask. Then, after using edge detection, the algorithm determined potential areas for further analysis. The geometrical parameters of the areas were determined on an 8-bit grayscale image. The following characteristics describing the areas were selected: perimeter, surface area, Feret diameters, Feret coefficient, circularity coefficient and dimensionless shape coefficient, Malinowska coefficient and moments. The set was randomly divided into 3 subsets, i.e. training (50\%), validation $(25 \%)$ and test $(25 \%)$, and normalized. Data prepared in this way were analysed for several selected models of neural networks, including a multilayer perceptron (with 9-71-1 structure), network of radial base functions, probabilistic neural network (with 933-1 structure). The best results of detection efficiency were obtained for the PNN (0.909) and MLP (0.813) networks. However, the authors do not mention how many images and elements were analysed, hence it is difficult to assess the universality and scope of applicability of the algorithm. In paper [17], the authors developed the method described in [16] by adding the possibility of classifying the types of determined defects in accordance with the ASTM E155 standard [18]. 300 images having a resolution of $1760 \times 2140$ pixels were used in the study. The localization process was similar to that described in [16]. The coefficients describing the detected, interesting areas, i.e. surface area, perimeter, Feret diameters, circularity and roundness coefficients, were adopted in the defect type classification process. A neural network was used as a block of classification. The selection of features fed to the network input was determined using a genetic algorithm. The best results were obtained for the network with the MLP 5-27-108 structure- the effectiveness of defect type classification was 0.93. Detection efficiency was as in [16]. Another solution was proposed in [19] where the algorithm 
was designed to classify the designated area into two classes: defect (D) or technological area (regular structures-RS). 72 $\mathrm{x}$-ray images with a resolution of $572 \times 768$ pixels were used in the study. $25 \%$ of the examined areas (defects) were the result of a technological process, the remaining $75 \%$ were artificially made by drilling holes with a small diameter. As a result, 424 potential areas with 214 defects and 210 artificial holes were obtained. It was assumed that defects could be characterized as groups of pixels in the image with a brightness level significantly different from their surroundings. The potential areas were located on the basis of pixel brightness analysis and edge detection. For this purpose, the LOG filter in combination with the zero crossing algorithm was used. The result was a binary image of the edges surrounding the potential defect areas. In the next step, a set of parameters describing the designated areas was determined. 8 parameters were adopted, including 3 geometrical ones and 5 related to area brightness (height, area width, surface area, mean brightness, mean second derivative values of pixels, crossing line profile, standard deviation of the vertical and horizontal profiles and high contrast ratio). The feature vector obtained in this way was fed to the input of the neural network. The experimentally selected network structure for which the best results were obtained contained one hidden layer with 11 neurons (8-11-1 network structure). The effectiveness of the algorithm was evaluated using cross-validation and the result was $90 \%$. Unfortunately, the study did not take into account the situation when technological holes are much larger than defects and their shape is not similar to a circle. The authors in [20] proposed a defect detection method based on a sequence of X-ray images (AMVI-Automated Multiple View Inspection) taken for the test element. In the first stage, the method involved taking a series of images and automatic marking of potential defects in all the images. In the second stage, tracking was performed for each selected area. As a result of the study, it was found that only the areas corresponding to the actual defects were tracked correctly in the entire sequence of images because the changes in their position were closely related to the change in the position of the examined element. The detection efficiency of $85.71 \%$ (TP / D) was achieved-Table 3. In papers [21-23], the authors discussed the principle of x-CT (x-ray computed tomography) and $\mu$-CT (microtomography) [23] as well as the process of image reconstruction and visualization. The advantages of x-CT-based methods in relation to standard radiography were also highlighted (the option of determining distribution, size and morphology of defects). The authors evaluated the defects using specially prepared software, but the process was carried out manually. Localization and measurement of defect parameters were performed by an operator. Due to the manual observation and measurement, the effectiveness of the developed solution was not presented. In publication [24], the authors discussed the current state of research related to $\mathrm{x}$-ray image analysis and processing in defect localization tasks and presented a brief review of defect recognition methods used so far. Next, the defect recognition methods chosen by the authors and their effectiveness for a sample set were presented. The set consisted of 47,500 fragments of x-ray images sized $32 \times 32$ pixels with or without defect areas. Some selected computer vision methods were used (deep learning, sparse representations, local descriptors and texture features). The best recognition results equal to $97 \%$ were obtained for the LBP descriptor (Local Binary Pattern) and the SVM linear classifier. When analysing the available literature, it can be observed that most solutions are based on the popular method of $\mathrm{x}$-ray radiography. In these cases, images obtained as a result of $\mathrm{x}$-raying the whole test element are analysed. There are also examples of using computed tomography, but the analysis process is performed manually. The main problems that appear in the above solutions are difficulties with the full automation of the image analysis process, the use of prepared image portions containing interesting areas, the need to adjust algorithm parameters or pre-select the areas. Taking into account the advantages of $\mathrm{x}-\mathrm{CT}$ and $\mu$-CT methods described in $[20,22,23]$ and potential possibilities, this paper proposes using these imaging methods in the process of automated defect localization and classification. This approach enables to detect defects, which are invisible when using standard techniques, and will provide the possibility of automatic estimation of the volume of such defects in the future.

In summary, the novelties of this method include:

- fully automatic segmentation of the tested elements in $\mu$-CT images;

- no need to adjust the algorithm parameters;

- a method of local threshold determination to eliminate groups of pixels on the edges of elements;

- a method of potential defect area detection using structural elements with a variable mask size;

- a proposal of a set of decryptors to describe defect areas;

- a proposal and construction of the D/ND area classifier using a neural network.

Due to the large number of studied images obtained for each element, the use of computer techniques seems necessary and justified. When analysing the available literature, the authors failed to find examples of algorithms for fully automatic defect localization that use images obtained from computed tomography ( $\mathrm{x}-\mathrm{CT}$ and $\mu$-CT). Therefore, the effectiveness of the proposed method has been compared with selected solutions based on images obtained from standard radiography (x-ray). 


\section{Material: collection of images}

Three aluminium elements with different structure, wall thickness and size, previously subjected to standard, manual quality control, were used in the study. The images were taken using the GE Phoenix vltomelx high-resolution x-ray system (microtomograph) at $200 \mathrm{kV}$ and $300 \mu \mathrm{A}$ in the Faculty Computed Microtomography Laboratory of the University of Silesia. The exposure time was $500 \mathrm{~ms}$. A series of 2000 images was taken for each element and then reconstruction was performed. As a result, images of layers were obtained, out of which the images containing the test element were selected. In total, there were 1200 (400 for each element) images of layers with different resolutions $(972 \times 1848$, $1276 \times 1589,1922 \times 1657)$ depending on the size of the element. Among potential areas for classification, the number of actual defects was 1255 and the number of technological holes (which are not defects) was 2083 based on the expert's assessment, with a total number of 3338 areas. Examples of images of the test elements in the form of 3D visualization and reconstructed layers are presented in Fig. 1a-c. Image areas where defects appear in the casting structure, which are significant from the point of view of assessing the element quality (large size, irregular structure, lower brightness than the surroundings), are marked in Fig. 1d-h. In these areas, the proposed algorithm should localize the existing defects. In the case of Fig. 1i, the defects in the structure of the entire element do not occur. The presented images show large variability of parameters in terms of brightness, size, shape of elements, number and size of technological holes, shape of areas of potential defects and artefacts related to the image acquisition process. The large variety of images enabled to verify the universality of the developed solution and test it in the widest possible range.

\section{Overview of the proposed approach}

The developed algorithm has been fully implemented in MATLAB. In order to facilitate the work, collection and presentation of results, an application with a simple user interface has been prepared. The scheme of the algorithm is presented in Fig. 2 and individual blocks are discussed in the following sections. The prepared set of images was automatically analysed by the algorithm and the values of parameters describing the designated areas were automatically determined. Then, the expert assessed each designated area, classifying it into two classes: D-defect, ND—nondefect. The data obtained in this way (1255-D and 2083-ND) were used to train the classifier and test the entire algorithm.

The parameters controlling the algorithm and the method of their determination are presented in Table 1. The only parameter set manually is the minimum defect size- $-\mathrm{AT}_{\mathrm{Min}}$.
For the test images (at the stage of preliminary analysis on a scale of 1:4), it was $\mathrm{AT}_{\mathrm{MinSc}}=3$ pixels. The minimum $\mathrm{AT}_{\mathrm{MinSc}}$ value enables to eliminate too small areas, irrelevant from the point of view of assessing the element quality and not being defects. The other parameters are set automatically. The initial element binarization threshold determined by the Otsu method allows to roughly determine the binary mask of the element. The local brightness threshold $T_{\mathrm{L}}$ (determined for each tested pixel of the element) enables to eliminate pixels (with a brightness greater than the global threshold $\left.T_{\mathrm{Otsu}}\right)$ located on the inner and outer edges of the element. This operation makes it possible to significantly reduce the number of individual pixels and small areas in the viccinity of the inner and outer edges of the element-Fig. 4e, f-Eq. (1).

\subsection{Preliminary assumptions}

Based on expert knowledge and literature [19,25] it was assumed that the areas interesting from the point of view of defect localization are characterized by the following features:

- brightness of defect pixels is smaller than surrounding brightness within the test element;

- brightness of defect pixels is greater than brightness of surrounding pixels outside the element;

- groups of darker pixels on the edges of the element are not defects;

- defect areas are characterized by heterogeneous texture;

- defect areas are characterized by an irregular shape;

- size, shape, orientation and location of defects are unknown;

- sizes of areas important from the point of view of the quality control process are greater than $\mathrm{AT}_{\mathrm{MinSc}}$ (Table 1) (3 pixels in the image in scale 1:4 -at the stage of area localization);

- some areas may be remnants of technological holes (on subsequent layers) and are not defects (these cases were the most difficult to classify).

Figure 3 presents examples of potential areas selected by the algorithm and marked by the expert as D-defects and ND_nondefects. The area D in Fig. 3a seem relatively easy to classify, their size is relatively large, the shape is irregular and their brightness is lower than the surrounding one. In turn, the areas assessed as ND are too small from the point of view of the quality control process. The situation looks slightly different in Fig. 3b. The element is not as compact as in the previous case, hence small defects may also affect the quality of the element. Here, however, defects seem easy to classify taking into account geometrical parameters or brightness distribution. Most of the pre-selected areas are characterized by much lower brightness in the defect area compared to the 
(a)

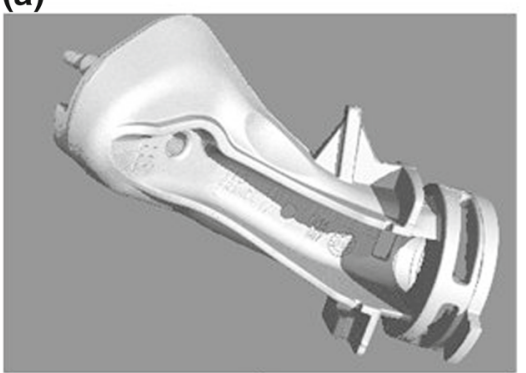

(d)

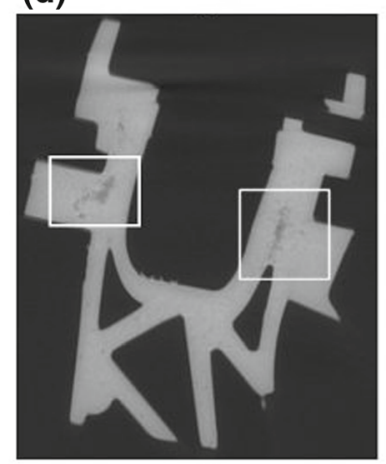

(g)

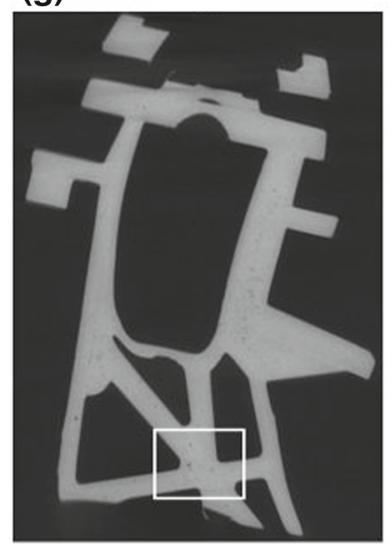

(b)

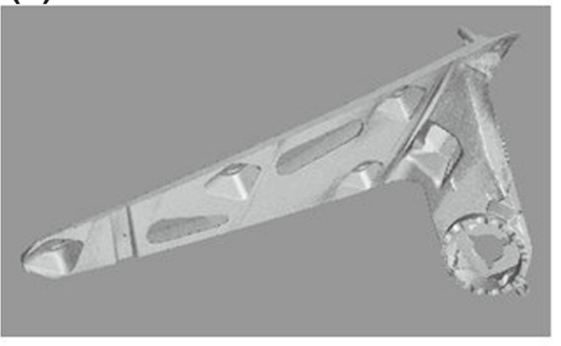

(e)

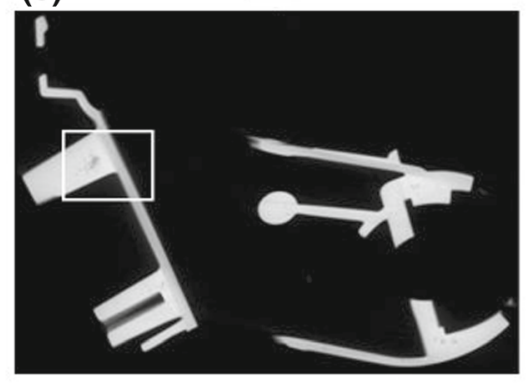

(h)

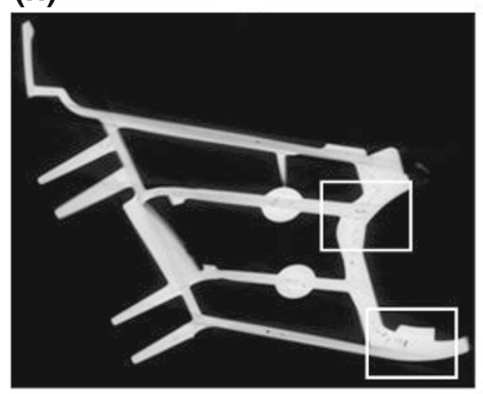

(c)

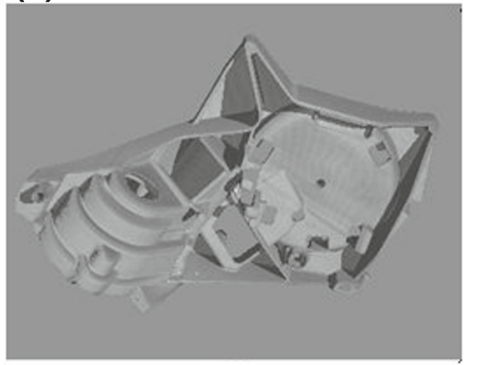

(f)

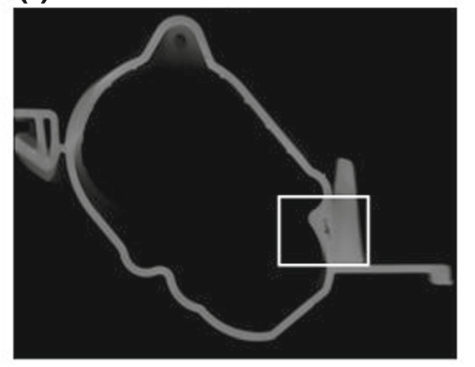

(i)

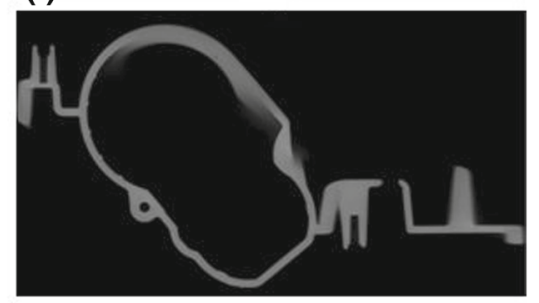

Fig. 1 Test elements, examples of layer images after reconstruction and potential defect areas

surrounding background and irregular shape. The situation is a bit more difficult in the case of Fig. 3c. Here, the areas of potential defects A, B are the result of a technological hole occurring in the previous layer. Such cases are the most difficult to classify even in the case of manual evaluation. In these cases, the expert's assessment was also based on the analysis of the previous and subsequent layers of the element. Based on the example of Fig. 3, only areas marked by the expert as D should be classified positively by the algorithm as TP. The other areas are the result of technological holes in other layers and should be classified as TN. In the discussed algorithm, the preliminary assumptions described above were adopted so as to correctly locate and classify the cases described here.

\subsection{Pre-processing and localization of areas}

At this stage, the most important task for the algorithm was to separate the area of the examined element from the image background. The Otsu method [20,26] was used to determine the automatic binarization threshold of the image $T_{\text {OTSU }}$, which allowed to effectively separate the element from the background. The element is presented in Fig. 4a and its binary mask in Fig. 4b.

Due to high resolution, the images were scaled (in the ratio $1: 4)$ at the stage of localization and detection of potential areas, whereas at the stage of determining the values of area features the full-resolution images were used. The next pre-processing step was to determine groups of pixels with brightness lower than the mean brightness $T_{\mathrm{G}}$ in 


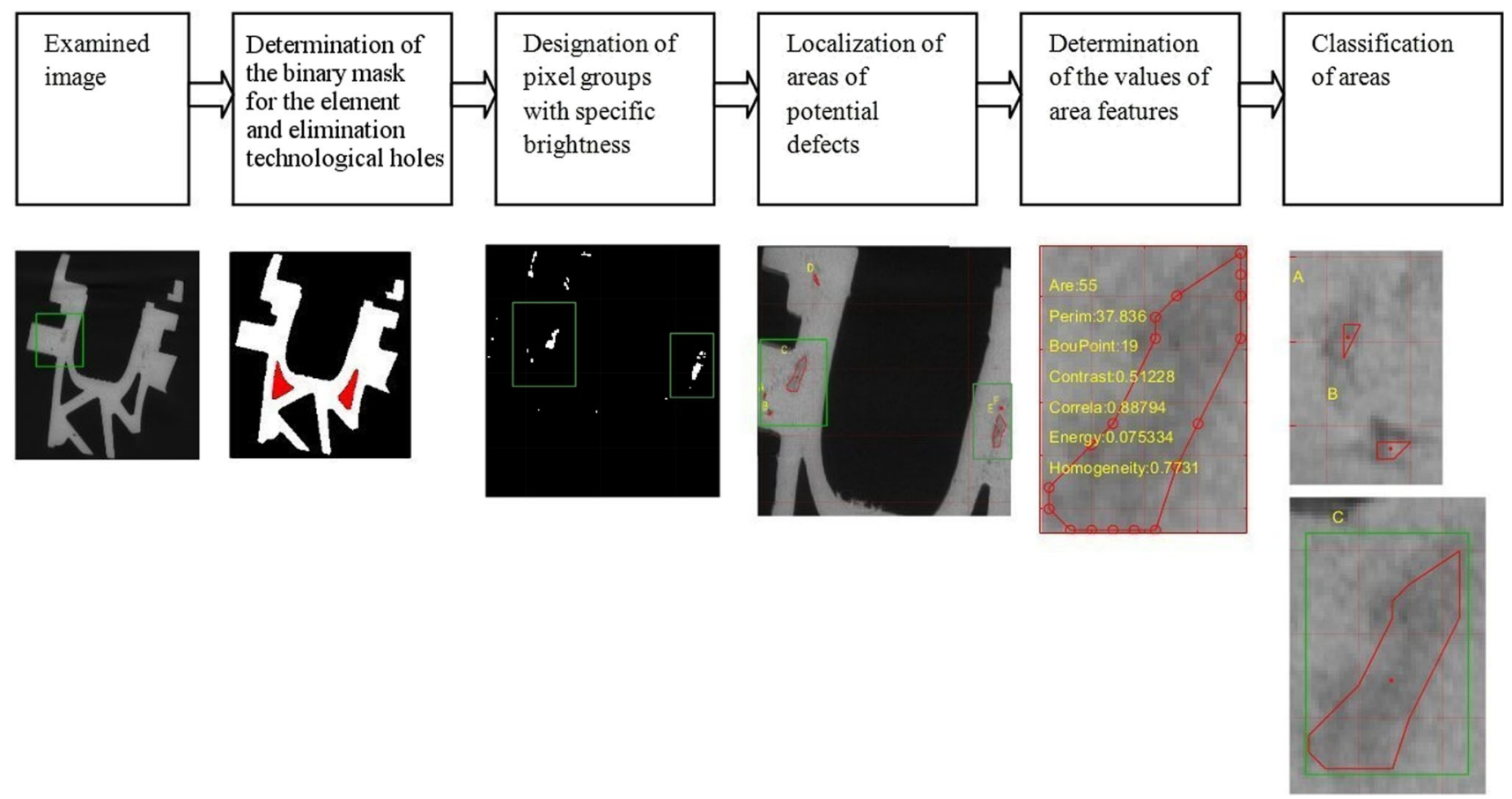

Fig. 2 Block diagram of the developed algorithm

Table 1 Algorithm parameters and determination method

\begin{tabular}{lll}
\hline Parameter & Value & Determination method \\
\hline Minimum area $\mathrm{AT}_{\text {MinSc }}$ & 3 pixels & Manual, experimental \\
Element binarisation threshold $T_{\text {Otsu }}$ & Otsu method & Automatic \\
Local brightness threshold $T_{\mathrm{L}}$ & $\begin{array}{l}\text { Depending on mean, } \\
\text { minimum, maximum } \\
\text { global brightness of } \\
\text { the element area and } \\
\text { distance function }\end{array}$ & \\
& Automatic, based on Eq. 1 and Fig. 4c, g \\
& \\
\hline
\end{tabular}

(a)

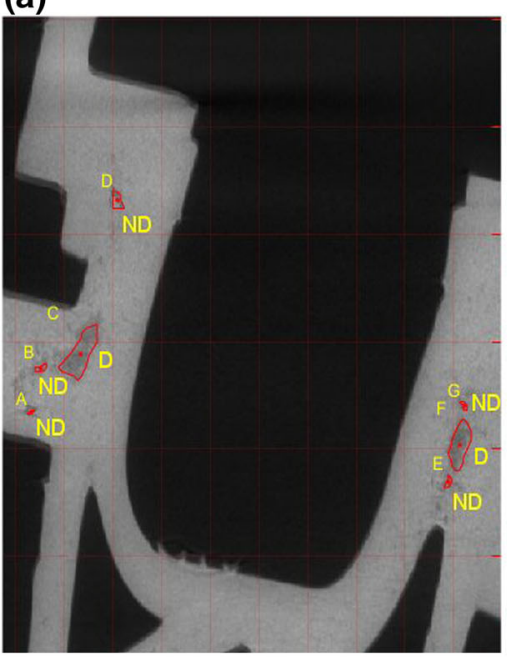

(b)

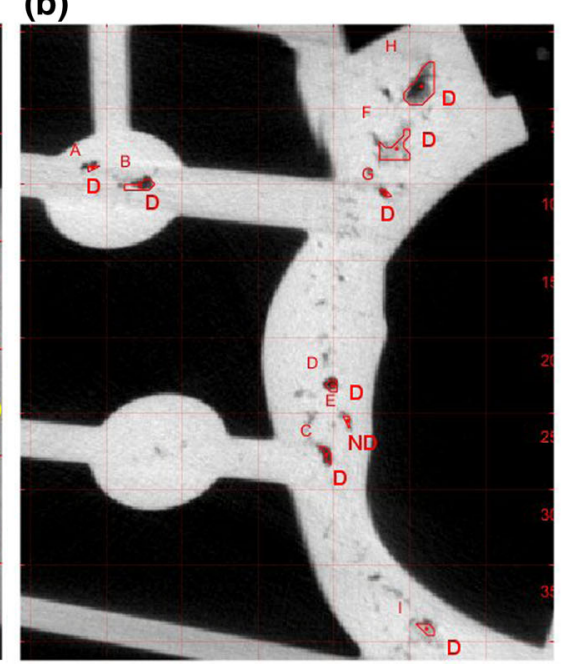

(c)

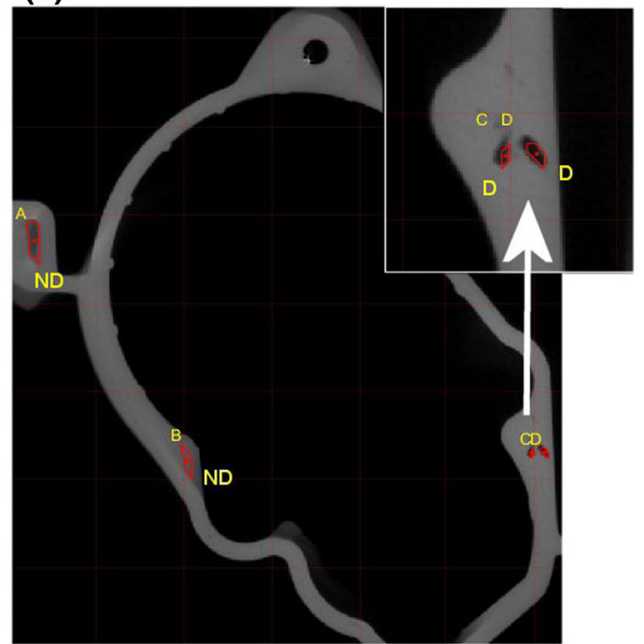

Fig. 3 Examples of D-defect and ND-nondefect areas and expert's assessment 
(a)

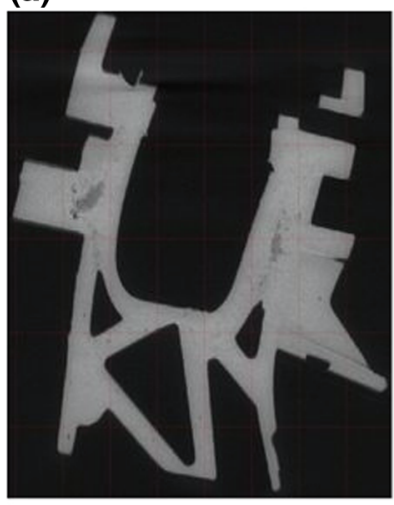

(e)

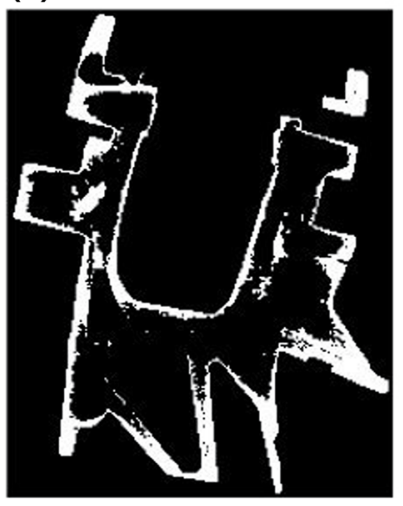

(b)

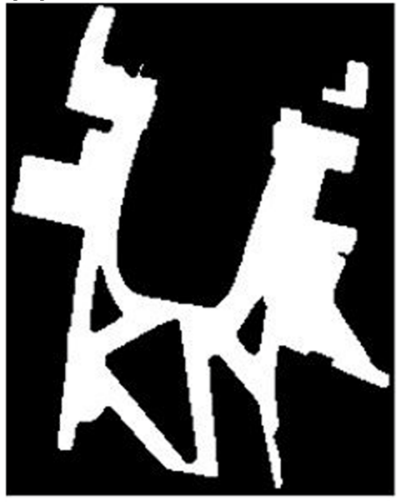

(f)

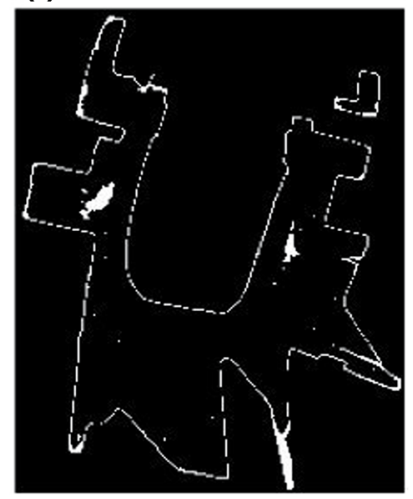

(c)

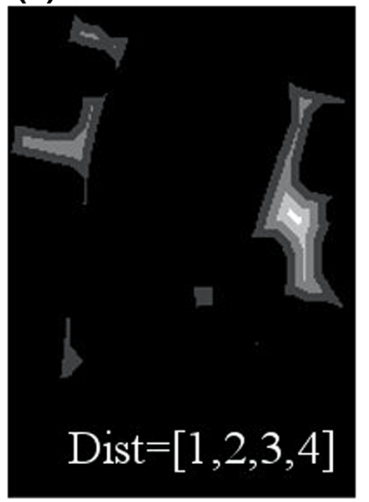

(d)

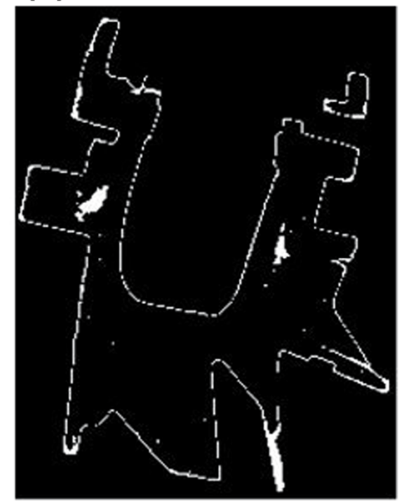

(g)

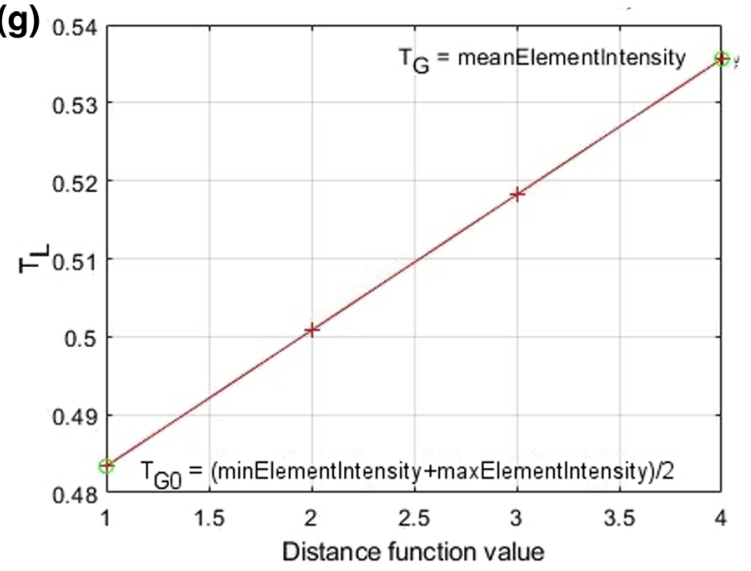

Fig. 4 Element and binary mask, distance function and resulting mask

the area of the test element and greater than the background brightness $-T_{\text {Otsu }}$. A method was developed for automatic determination of the threshold $T_{\mathrm{G}}$ based on the global mean brightness value $I_{\text {Mean }}$ of the pixels belonging to the element (Fig. 4a) and the local one $T_{\mathrm{L}}$ related to the distance of the examined pixel from the edge, determined by means of the distance function [27]. The values obtained from the distance function (Fig. 4c) - calculated as the number of successive erosions with a 'disk' element SE sized $5 \times 5$ pixels) allowed for slight adjustment of the threshold $T_{\mathrm{L}}$ depending on the distance of the pixel from the edge of the test element.

The values obtained from the distance function (Fig. 4c) enabled to slightly adjust the global threshold value $T_{\mathrm{G}}$ and determine the local threshold $T_{\mathrm{L}}$ (1)-Fig. 4g. Figure $4 \mathrm{e}$ (for comparison) shows groups of pixels determined based on the global threshold $T_{\mathrm{G}}$, and Fig. $4 \mathrm{f}$-based on $T_{\mathrm{L}}$. It can be observed that as a result of this operation, the local threshold $T_{\mathrm{L}}$ had a slightly lower value closer to the edge of the element,

which allowed to eliminate some dark pixels belonging to the edge of the element Fig. 4f. On the other hand, inside the element, the value of $T_{\mathrm{L}}$ slightly increased $\left(T_{\mathrm{L}} \leq T_{\mathrm{G}}\right.$-Fig. $\left.4 \mathrm{~g}\right)$, which allowed to locate slightly brighter pixels located near the searched areas. The threshold $T_{\mathrm{L}}$ and darker pixels of element are determined based on Eq. (1):

$$
\begin{aligned}
& T_{\mathrm{L}}(x, y)=T_{\mathrm{G} 0}+T_{\mathrm{Dist}}(x, y) \\
& I_{\mathrm{TL}}(x, y)= \begin{cases}I(x, y) & \text { if } I(x, y) \leq T_{\mathrm{L}} \\
0 & \text { if } I(x, y)>T_{\mathrm{L}}\end{cases}
\end{aligned}
$$

where $T_{\mathrm{L}}$ automatically determined local threshold value for analysed pixel in $x, y, T_{\mathrm{G} 0}$ sum of min and max element intensity (pixels with intensity above $T_{\text {Otsu }}$ ) divided by $2, T_{\text {Dist }}$ threshold increase based on value of distance function in $x$, $y$-Fig. 4c, g, $I(x, y)$ analysed image—pixels with intensity above $T_{\mathrm{Otsu}}, I_{\mathrm{TL}}(x, y)$ image with pixels with intensity $\leq T_{\mathrm{L}}$. 
Fig. 5 Elimination of edge pixels whose surroundings contain pixels with brightness below the designated threshold $T_{\text {OTSU }}(\mathbf{d}-\mathbf{f})$

Fig. 6 Preliminary analysis of area masks by means of minimum filters of various sizes

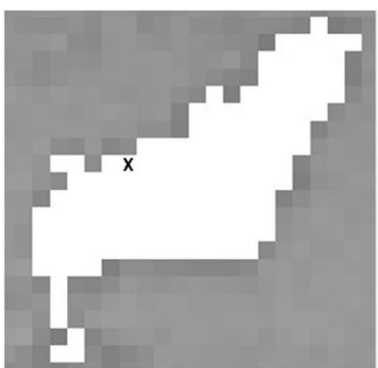

(a)

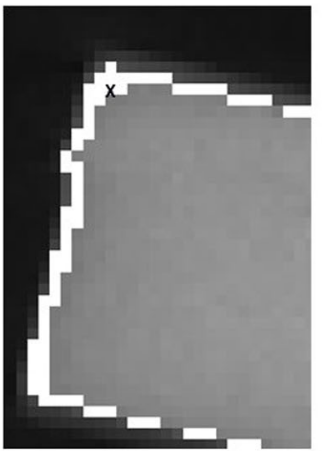

(d)

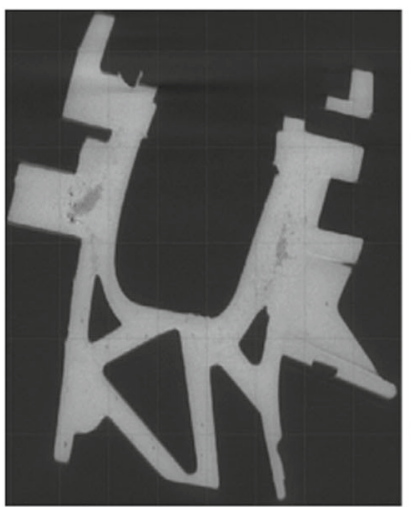

(a)

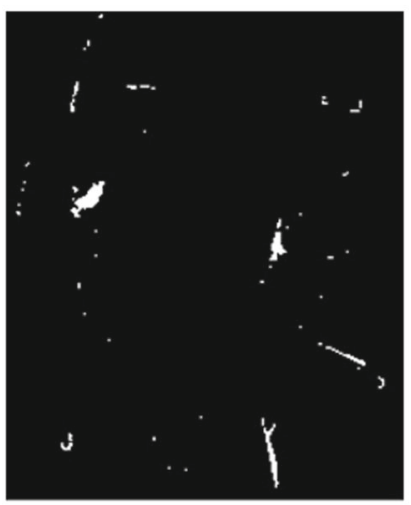

(d) $\mathrm{SE}=5 \times 5$

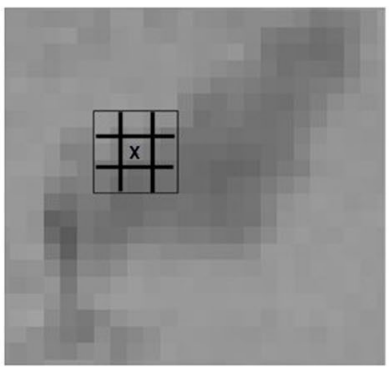

(b) $\mathrm{SE}=3 \times 3$

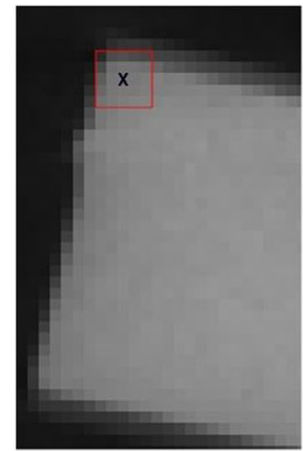

(e) $\mathrm{SE}=3 \times 3$

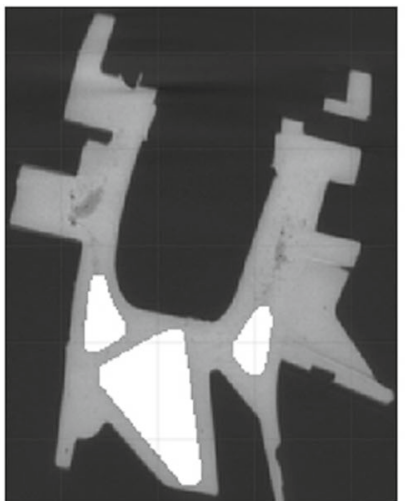

(b)

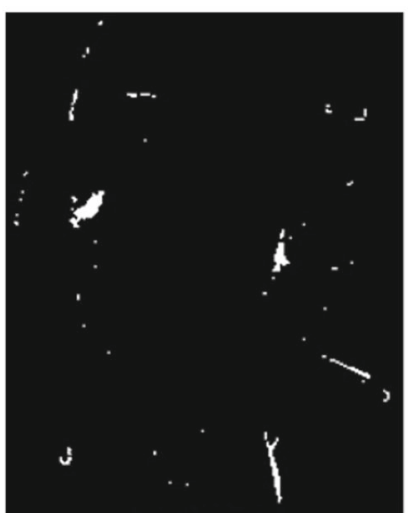

(e) $\mathrm{SE}=7 \times 7$

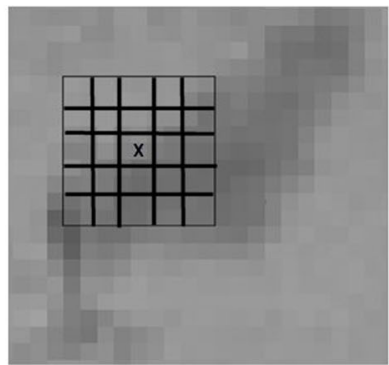

(c) $\mathrm{SE}=5 \mathrm{x} 5$

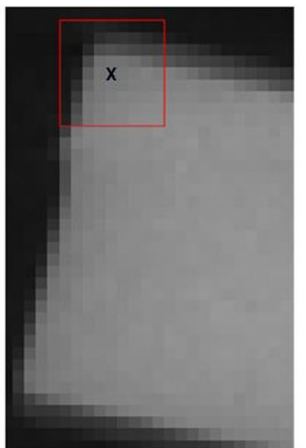

(f) $\mathrm{SE}=5 \times 5$

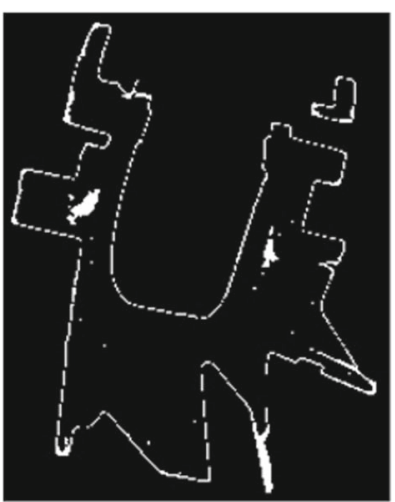

(c) $\mathrm{SE}=3 \times 3$

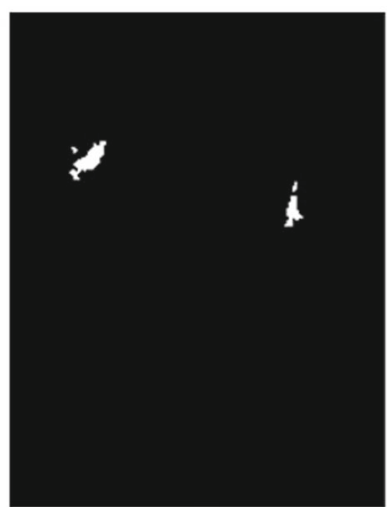

(f) 
In the next step, the edges of the element are removed by analyse the $(3 \times 3)$ surroundings of each pixel, based on $(2)$ :

$$
I_{\mathrm{Bin}}(x, y)= \begin{cases}1 & \text { if } \min _{m_{i}, n_{i} \in B_{3 x 3}(x, y)}\left(I_{\mathrm{TL}}\left(m_{i}, n_{i}\right)\right)>T_{\mathrm{Otsu}} \\ 0 & \text { if } \min _{m_{i}, n_{i} \in B_{3 \times 3}(x, y)}\left(I_{\mathrm{TL}}\left(m_{i}, n_{i}\right)\right) \leq T_{\mathrm{Otsu}}\end{cases}
$$$$
I_{\mathrm{GB}}(x, y)=I_{\mathrm{TL}}(x, y) * I_{\mathrm{Bin}}(x, y)
$$

where $I_{\mathrm{TL}}$ image with pixels with intensity $\leq T_{\mathrm{L}}, I_{\mathrm{Bin}}(x, y)$ binary mask of pixels that satisfy the condition-(Fig. 4d), $T_{\mathrm{Otsu}}$ automatically determined threshold in image, $I_{\mathrm{GB}}$ element in gray image after background elimination.

Pixels with brightness lower than the threshold $T_{\mathrm{G}}$ and greater than the background brightness $T_{\text {OTSU }}$ were marked in the binary image representing the area masks. The pixels determined in this way belonged to 3 groups-Fig. 4 d, f:

- the remaining pixels belonging to the edge of the element whose lower brightness value is associated with the impact of background brightness;

- pixels belonging to the areas of technological holes or their remnants (in other layers) — not being defects;

- proper pixels belonging to defect areas.

The last pre-processing operation was the elimination of large internal holes resulting from the shape of the element-Fig. 6b. For this purpose, the flood-fill operation was used [27]. Then, based on the assessment of the shape of these areas, they were classified as large technological holes (areaValue/perimeterValue $<1$ ).

Large technological holes whose brightness was similar to the background brightness, i.e. lower than $T_{\mathrm{OTSU}}$, were eliminated. Assuming an unknown size of defects, a solution based on the use of minimum filters with an increasing mask size was developed in order to locate groups of pixels within the element. The surroundings for each previously designated binary mask pixel (Fig. 4d, f) were analysed with a 2 minimum filters (erosion in gray image) to check if there were no background pixels. When a background pixel was present (the analysed pixel belonging to the edge or placed close to the edge), the determined minimum value in its surroundings was smaller than the previously determined threshold $T_{\text {OTSU }}$. Such a pixel was then reduced and the area mask was reduced. This operation effectively eliminated edge pixels that were previously selected based on Eqs. (1), (2) and (3)

$$
\begin{gathered}
I_{s 3 x 3}(x, y)=\min _{m_{i}, n_{i} \in B_{3 x 3}(x, y)}\left(I_{\mathrm{GB}}\left(m_{i}, n_{i}\right)\right) \\
I_{s 5 x 5}(x, y)=\min _{m_{i}, n_{i} \in B_{5 x 5}(x, y)}\left(I_{\mathrm{GB}}\left(m_{i}, n_{i}\right)\right) \\
I_{\mathrm{Bin} 3 x 3}(x, y)= \begin{cases}1 & \text { if } I_{s 3 x 3}(x, y)>0 \\
0 & \text { if } I_{s 3 x 3}(x, y)=0\end{cases} \\
I_{\mathrm{Bin} 5 x 5}(x, y)= \begin{cases}1 & \text { if } I_{s 5 x 5}(x, y)>0 \\
0 & \text { if } I_{5 x 5}(x, y)=0\end{cases}
\end{gathered}
$$

where $I_{\mathrm{GB}}$ intensity in image in grayscale Fig. 6a, Eq. (1), $I_{s 3 \times 3}, I_{s 5 \times 5}$ image after using the minimum filter, $I_{\mathrm{Bin} 3 \times 3}$, $I_{\text {Bin5 } x 5}$ images $I_{s 3 \times 3}, I_{s 5 x 5}$ after thresholding Fig. $6 \mathrm{c}, \mathrm{d}$.

An example of determining the minimum value of the surroundings is shown in Fig. 5a (inside the element) and Fig. 5d (on the element edge). It can be observed in Fig. 5b, c that the surroundings of the pixel are analysed in the increasing square area $\mathrm{SE}=3 \times 3$ and $\mathrm{SE}=5 \times 5$ but there are no dark pixels (with intensity $=0$ ) of the background so the mask is not reduced. Figure 5 e shows that in the $3 \times 3$ surroundings there are no background pixels, but in the $5 \times 5$ surroundings they appear, and this mask pixel Fig. $5 \mathrm{~d}$ will be therefore reduced.

It can be observed in Fig. 6 that the reduced binary mask from Fig. $4 \mathrm{~d}$, $f$ after using minimum filters of increasing size $((\mathrm{SE}=3 \times 3, \mathrm{SE}=5 \times 5, \mathrm{SE}=7 \times 7)$ Fig. $6 \mathrm{c}-\mathrm{e})$ does not change in the areas designated inside the element (the surface area and shape are the same), while the areas belonging to the edge of the element are reduced due to the lower pixel brightness of the background surrounding the test element. The conducted tests have allowed to determine that the mask sizes $\mathrm{SE}=3 \times 3$ and $\mathrm{SE}=5 \times 5$ are sufficient for effective separation of potential areas of defects. The last stage of locating potential areas of defects was the comparison of their geometrical parameters. These area masks which in the binary images (after applying the minimum filters $\mathrm{SE}=3$ $\times 3$ and SE $=5 \times 5$-Fig. $6 \mathrm{c}$, d) had the same values of the surface area and centroid coordinates were classified as a potential defect regions within the element and were subjected to further analysis-Fig. 6f. At this stage, the expert classified the whole set of the designated areas, selecting the areas of defects D and technological holes ND. Figure $6 f$ shows the final result of this operation in the form of groups of pixels located inside the test element. The pixels near the edges have been completely removed. This procedure is shown in Algorithm 1. 


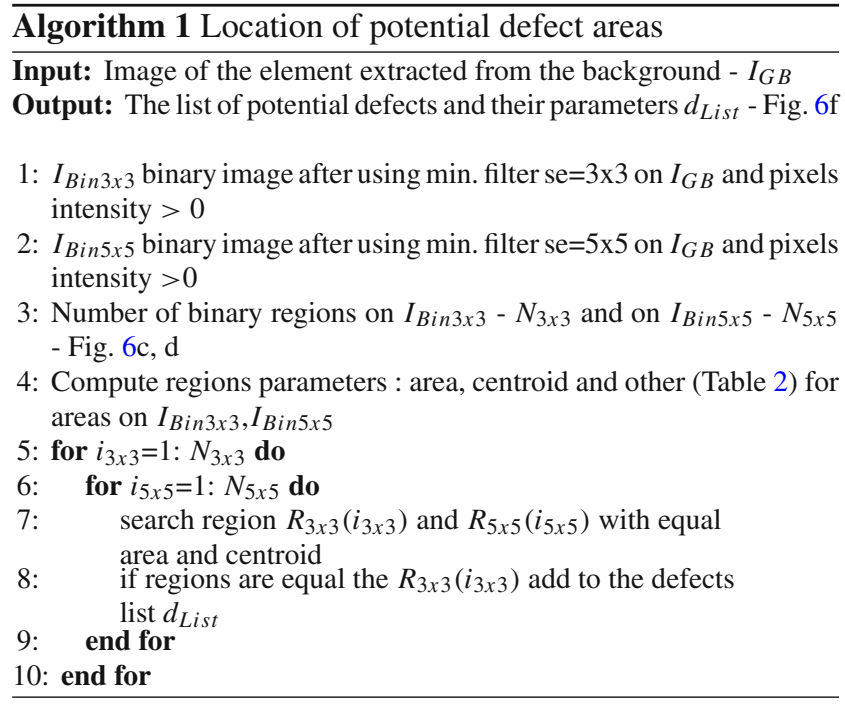

\subsection{Generation and selection of values of area features}

The areas designated by the method shown in Fig. 6 were subjected to quantitative analysis in order to determine the values of their features.

In order to prepare a set of features describing defect areas, the available literature on the previously used x-ray descriptors [15-17,19,20], universal image descriptors [28,29] and complex methods, e.g. CNN-based descriptors [30,31], LBP [32] and unsupervised learning [33], was analysed.

During tests and preparation of the set of images, the correct defect localization and classification by the expert were mostly affected by the contrast, brightness inside and outside the area, its irregular shape, and, to a lesser extent, by a specific texture pattern. Therefore, area descriptors and statistical texture descriptors, which are similar to those proposed in the analyzed literature for $\mathrm{x}$-ray images, and some universal descriptors were selected-Table 2. More complex methods of generating features can achieve similar or even higher efficiency. Features will be generated automatically but these methods will require a much larger training set of images [30]. The methods based on LBP [32] are very popular and effective, but their computational complexity is slightly higher. Therefore, when analysing multiple layers, the analysis time may be longer. The situation is similar in the case of unsupervised feature generation methods proposed in [33]. Here, the authors also point out the need for more computing power.

After having analysed the available literature [15-17,19, $20,28,29]$, a set of 21 features was proposed by means of which the analysed areas were described. These features formed a vector that was used in further research (4) during the construction of the classifier:

$\mathbf{Z}=\left(Z_{1}, \cdots Z_{21}\right)^{\mathrm{T}}$

The set of features included basic geometrical, morphological and texture parameters [28,29,34,35] and additional features determined on their basis. The selected parameters were described in sequence and presented in a graphical form in Fig. 7. Table 2 presents the full list of the features used in further research together with basic statistical information before normalization. The parameter maxElementIntensity is the maximum value of brightness in the image, and otsuThresholdValue is the automatically determined threshold (Sect. 4.2 $\left.T_{\mathrm{OTSU}}\right)$. The parameters areaSurface, areaEccentricity, areaSurface2areaBoundBox,areaMeanIntensity, areaStdIntensity were determined based on the binary mask of the designated area and the pixels of the examined image which the mask included Fig. 7a. The parameter areaMeanAroundIntensity is the mean brightness of the pixels around the studied area. The binary mask of the surroundings was generated as a result of dilation of the area mask with the element $\mathrm{SE}=3 \times 3$-Fig. $7 \mathrm{~b}$.

The parameters areaContrastTex, areaCorrelationTex, areaEnergyTex, areaHomogeneityTex are standard texture parameters generated on the basis of the normalized cooccurrence matrix $N_{\mathrm{G}}[28,36]$ and described by the following equations (5) :

$$
\begin{aligned}
& \text { areaContrastTex }=\sum_{i} \sum_{j}(i-j)^{2} N_{g}(i, j) \\
& \text { areaCorrelationTex }=\frac{\sum_{i} \sum_{j}\left(i-\mu_{i}\right)\left(j-\mu_{j}\right) N_{g}(i, j)}{\sigma_{i} \sigma_{j}} \\
& \text { areaEnergyTex }=\sum_{i} \sum_{j} N_{g}^{2}(i, j) \\
& \text { areaHomogeneityTex }=\sum_{i} \sum_{j} \frac{N_{g}(i, j)}{1+|i-j|}
\end{aligned}
$$

where $i, j$ are the numbers of the row and column of the co-occurrence matrix $N_{\mathrm{G}}, \mu_{i}, \mu_{j}$ and $\sigma_{i}, \sigma_{j}$ are the means and standard deviations of the row $i$ and column $j$.

The areaBoudaryPolygon is the number of points around the boundary, which is a polygon-Fig. $7 \mathrm{~d}$. The parameter areaThinessRatio described by Eq. (6) determines the irregularity of the area shape.

areaThiness Ratio $=\frac{4 * \pi * \text { areaSurface }}{\text { areaPerimeter }}{ }^{2}$ 
Fig. 7 Graphic presentation of the selected parameters of the studied areas (a)
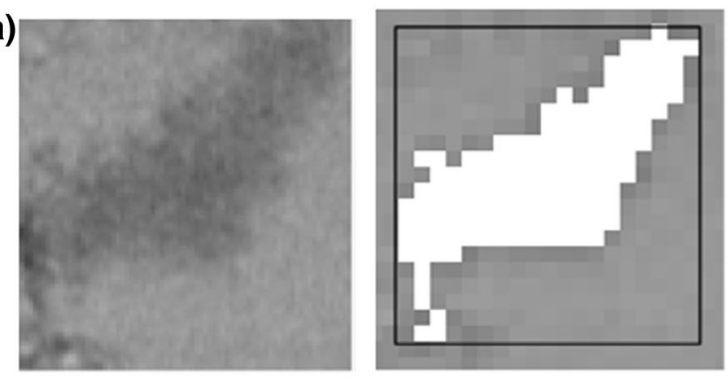

(c)

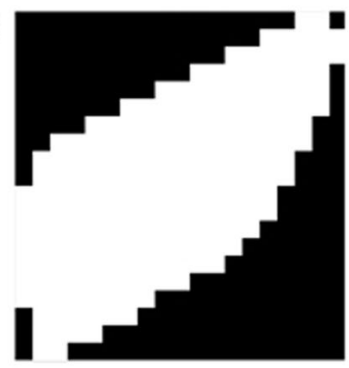

(b)

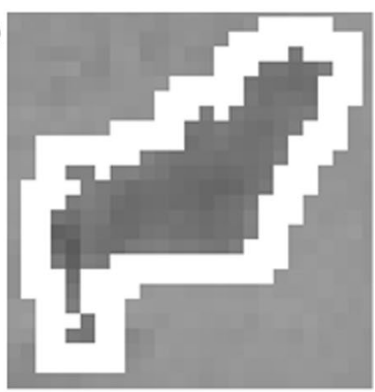

(d)

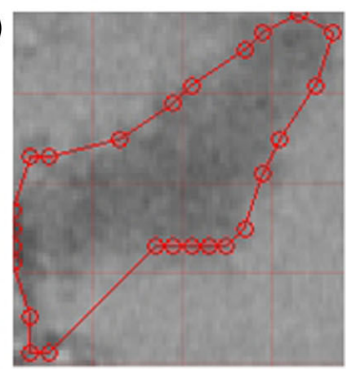

The convexSurface and convexPerimeter are the surface area and perimeter of the polygon surrounding the examined area-Fig. 7c. The features $Z_{15}$ and $Z_{19}-Z_{21}$ have been described in the form of dependencies, as a result of which they were determined in Table 2 . The determined parameters of features, before being fed to the classifier input, were normalized (relative to the minimum and maximum values in the range of 0-1) [37] to eliminate the impact of large values.

\subsection{Classification of designated areas}

After automatic localization of potential areas, which may be defects in the test element, a neural-network-based classifier was designed. After analysing the literature on the construction of neural networks [25,37-39], a feedforward network with a sigmoid activation function with 9 inputs with 1 hidden layer (4 neurons) and 1 output was proposed. To describe the quality of the tested classifier configurations, the Accuracy (ACC) parameter (defining the best ratio of correct defect and nondefect detections to the number of all examined areas) was used at this stage, which was also applied in compared publications $[16,19,20]$ and described in Table 3 . At the beginning of the classifier construction process, a subset of 9 features was used, successively increased to 13,18 , 21 in order to compare the obtained results. The effects were unsatisfactory, ACC around 50\%. Therefore, based on correlation, individual parameters were compared with the set values (areas of defects indicated by the expert) [37]. This demonstrated a particularly strong correlation of the variable $Z_{7}$ (equal to $r=0.44$ with the set values) compared to other variables, which interfered with their impact on the obtained classification results. Therefore, the feature $Z_{7}$ was
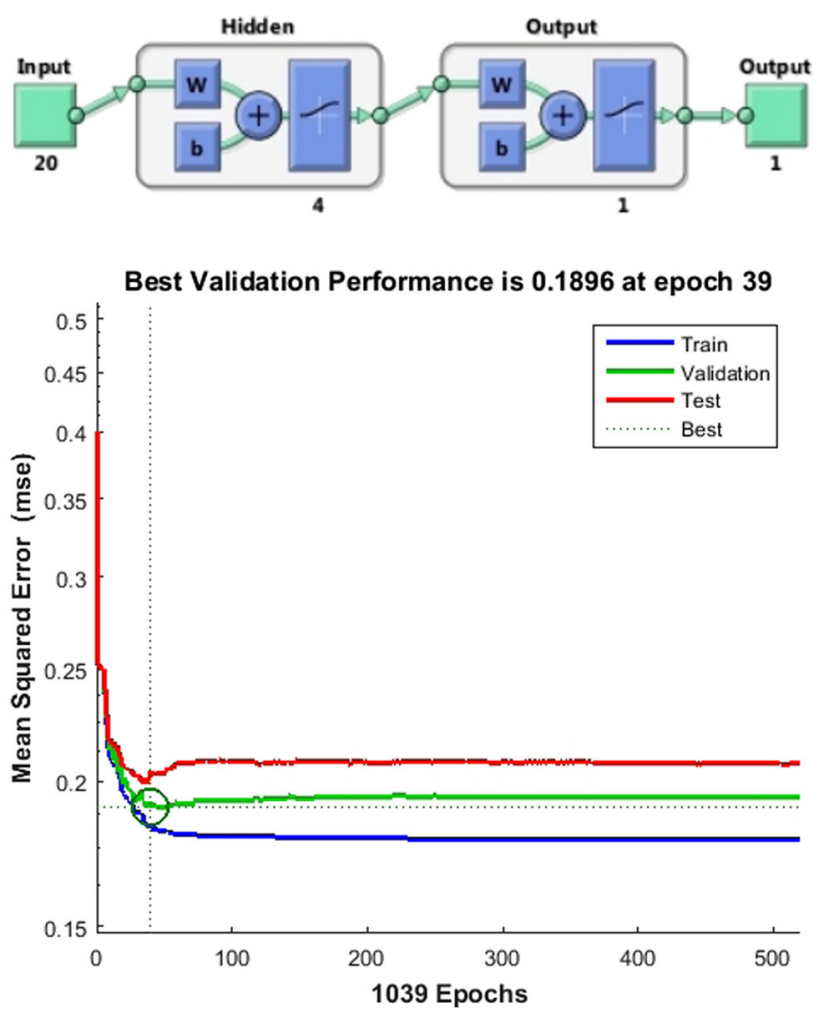

Fig. 8 Structure of the neural network and number of epochs versus mean square error

removed from the classifier input vector $\mathbf{Z}$, which positively influenced its operation, and a variant of the neural network with the 8-4-1 structure was adopted in further research. After removing the variable $Z_{7}$, the features directly related to the brightness of areas and geometrical data $\left(Z_{1}-Z_{9}\right)$ 
Table 2 Statistical information on the area features

\begin{tabular}{|c|c|c|c|c|c|c|}
\hline No. & Selected feature & Symbol & Min. value & Max. value & Mean & Std. \\
\hline 1 & maxElementIntensity & $Z_{1}$ & 0.46 & 1 & 0.69 & 0.13 \\
\hline 2 & otsuThresholdValue & $Z_{2}$ & 0.16 & 0.38 & 0.30 & 0.05 \\
\hline 3 & areaSurface & $Z_{3}$ & 4 & 251 & 15.15 & 24.99 \\
\hline 4 & areaEccentricity & $Z_{4}$ & 0 & 0.99 & 0.70 & 0.31 \\
\hline 5 & areaSurface 2 areaBoundBox & $Z_{5}$ & 0.10 & 1 & 0.67 & 0.20 \\
\hline 6 & areaMeanIntensity & $Z_{6}$ & 0.18 & 0.75 & 0.46 & 0.09 \\
\hline 7 & areaMeanAroundIntensity & $Z_{7}$ & 0.28 & 0.86 & 0.58 & 0.13 \\
\hline 8 & areaStdIntensity & $Z_{8}$ & $5.88 \mathrm{e}-17$ & 0.15 & 0.04 & 0.02 \\
\hline 9 & areaPerimeter & $Z_{9}$ & 3.55 & 135.27 & 12.18 & 13.48 \\
\hline 10 & areaContrastTex & $Z_{10}$ & 0.06 & 5.96 & 1.15 & 0.64 \\
\hline 11 & areaCorrelationTex & $Z_{11}$ & 0.15 & 0.99 & 0.84 & 0.10 \\
\hline 12 & areaEnergyTex & $Z_{12}$ & 0.03 & 0.75 & 0.08 & 0.04 \\
\hline 13 & areaHomogeneityTex & $Z_{13}$ & 0.47 & 0.96 & 0.71 & 0.08 \\
\hline 14 & areaBoudaryPolygon & $Z_{14}$ & 0 & 50 & 8.94 & 5.49 \\
\hline 15 & areaSolidity $\left(Z_{3} / Z_{1} 7\right)$ & $Z_{15}$ & 0.34 & 1 & 0.89 & 0.12 \\
\hline 16 & areaThinessRatio & $Z_{16}$ & 0.12 & 3.97 & 1.76 & 1.07 \\
\hline 17 & convexSurface & $Z_{17}$ & 4 & 625 & 19.42 & 37.63 \\
\hline 18 & convexPerimeter & $Z_{18}$ & 3.55 & 132.44 & 11.46 & 11.62 \\
\hline 19 & areaPerim2convPerim $\left(Z_{9} / Z_{18}\right)$ & $Z_{19}$ & 0.97 & 1.68 & 1.03 & 0.07 \\
\hline 20 & areaMean2areaStd $\left(Z_{6} / Z_{8}\right)$ & $Z_{20}$ & 3.60 & $5.17 \mathrm{e}+15$ & $3.21 \mathrm{e}+12$ & $1.25 \mathrm{e}+14$ \\
\hline 21 & areaMean2maxElIntensity $\left(Z_{6} / Z_{1}\right)$ & $Z_{21}$ & 0.39 & 0.85 & 0.67 & 0.07 \\
\hline
\end{tabular}

Table 3 Comparison of results obtained for the selected solutions

\begin{tabular}{|c|c|c|c|c|c|}
\hline Method & Number of images & $\begin{array}{l}\text { Total number of } \\
\text { defects/nondefects } \\
\text { D/ND }\end{array}$ & $\begin{array}{l}\mathrm{ACC}_{\mathrm{CVMean}} \\
\mathrm{ACC}_{\mathrm{CVMax}} \\
\frac{\mathrm{TP}+\mathrm{TN}}{\mathrm{D}+\mathrm{ND}} \\
\end{array}$ & $\begin{array}{l}\text { Detection perfor- } \\
\text { mance (DP) } \\
\frac{\mathrm{TP}}{\mathrm{D}}\end{array}$ & AUC Fig. 9 \\
\hline Method 1 [16] & N/A & N/A & $\begin{array}{l}\text { N/A } \\
81-90 \%\end{array}$ & N/A & N/A \\
\hline Method 2 [19] & 72 & $214 / 210$ & $\begin{array}{l}90.3 \% \\
95.3 \%\end{array}$ & N/A & 0.96 \\
\hline Method 3 [20] & 72 & $238 / 253$ & N/A & $85.71 \%$ & N/A \\
\hline $\begin{array}{l}\text { Method } 4 \\
\text { Proposed method }\end{array}$ & 1200 & $1255 / 2083$ & $\begin{array}{l}86.5 \% \\
89.1 \%\end{array}$ & $\begin{array}{l}85.6 \% \\
85.22 \%\end{array}$ & 0.89 \\
\hline
\end{tabular}

were proposed as an input vector, which provided $\mathrm{ACC}=$ $81.81 \%$. Then, attempts were made to verify the effectiveness by adding features related to the texture of the studied areas $\left(Z_{10}-Z_{13}\right)$, which helped to obtain better results$\mathrm{ACC}=85.23 \%$. In the next stage, $\left(Z_{14}-Z_{18}\right)$ parameters that define irregularities in the shape of the areas were added to the feature vector, yielding ACC $=86.99 \%$. Finally, the features artificially generated based on the basic features $\left(Z_{19}-Z_{21}\right)$ were added, and the result obtained in this case was ACC = $89.01 \%$. For each case, 5 network training/testing attempts were made and the best solution was chosen, which was a neural network with 20 inputs, 4 neurons in the hidden layer and 1 neuron in the output layer (20-4-1) -Fig. 8. A network output value greater than 0.5 was classified as a defect area. The system performance is analysed in terms of number of epochs versus MSE (Fig. 8). The best validation performance in terms of MSE is 0.1896 at epoch 39.

\subsection{Results and discussion}

In order to fully evaluate the developed algorithm and the selected variant of the neural network and to compare it with the mentioned publications $[16,19,20]$, three parameters were applied, i.e. Accuracy $(A C C)$, Detection performance 


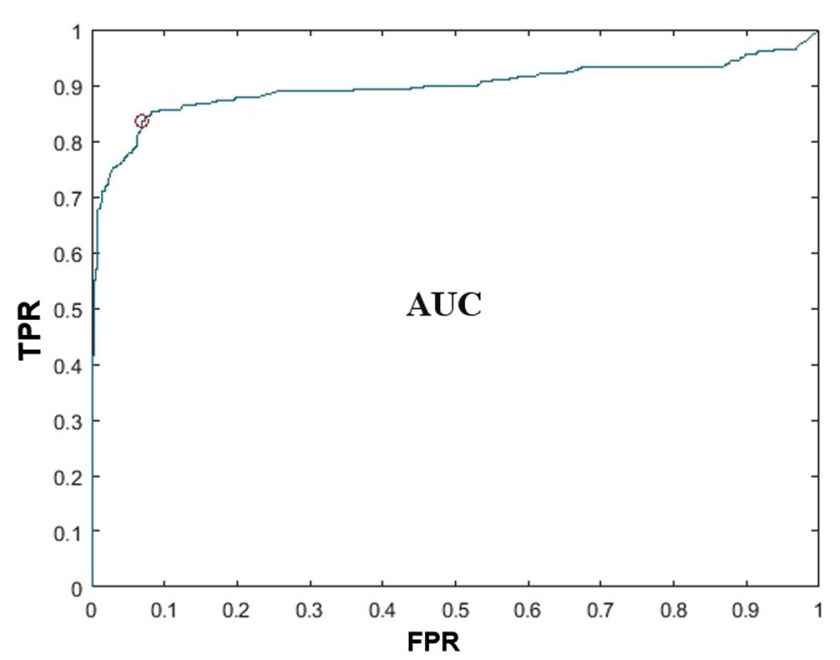

Fig. 9 ROC curve for the best classifier variant (20-4-1)

$(D P)$ and ROC curve (AUC - Area Under Curve), which are described in the form of equations in the respective columns in Table 3. Figure 9 presents the ROC chart for the classifier in 20-4-1 configuration with the input vector of features $\mathbf{Z}$ as below (7).

\section{$\mathbf{Z}=\left(Z_{1}, \ldots Z_{n}\right)^{\mathrm{T}}$}

$n \in\{1,2,3,4,5,6,8,9$,

$10,11,12,13,14,15,16,17,18,19,20,21\}$

The effectiveness of the developed algorithm was verified on the basis of error matrix analysis [19,37]. The values of $\mathrm{TP}, \mathrm{TN}, \mathrm{FP}, \mathrm{FN}$ were determined from the error matrix and on their basis the basic measures of the classifier quality were calculated. Situations in which the algorithm correctly identified the actual areas of defects were adopted as TP (375). TN (638) were cases when the areas being technological holes or their remnants (on successive layers) were correctly recognized as nondefects. FP detections (60) were situations when technological holes were recognized as defects, and FN (65) when defect areas were not identified. As a result, the following values were obtained: $\mathrm{ACC}=89.01 \%$, DP $=85.22 \%$ and $\mathrm{AUC}=0.89-$ Table 3. The applied test set included 1138 randomly selected, potential areas for classification, where the number of actual defects $\mathrm{D}$ was equal to 440 and ND $=698$. The authors could not find in the available literature algorithms intended for automatic localization and classification of defects for $\mathrm{x}-\mathrm{CT}$ or $\mu$-CT images after reconstruction. Therefore, Table 3 compares the effectiveness of the developed method with the selected solutions based on standard x-ray images, which were discussed above. The assessment was carried out on the basis of parameters proposed by other authors and the results obtained for test sets. The Accuracy parameter was presented as the best ACC value $\left(\mathrm{ACC}_{\mathrm{CVMax}}\right)$ and the mean value obtained from crossvalidation $\mathrm{ACC}_{\mathrm{CVM}}$ ean (when the authors presented such data in their publications).

In order to confirm the effectiveness of the classifier under different conditions (for different subsets of data), the model was evaluated (similarly as in [19]) by means of foldfold cross validation, for randomly generated 10 sets (training set to test set in a ratio of 9-1). The mean value in cross-validation was $\mathrm{ACC}_{\mathrm{CVMean}}=86.5 \%$ and $\mathrm{DP}=85.6 \%$ (according to the formulas in Table 3). The values were not much lower than the best results obtained at the stage of experiments with the classifier construction (where 2200 and 1138 areas were used as a training and test sets, respectively—described (a)

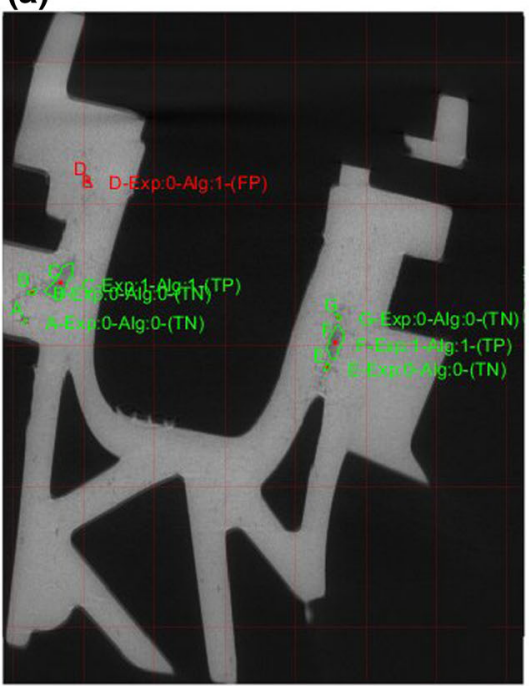

(b)

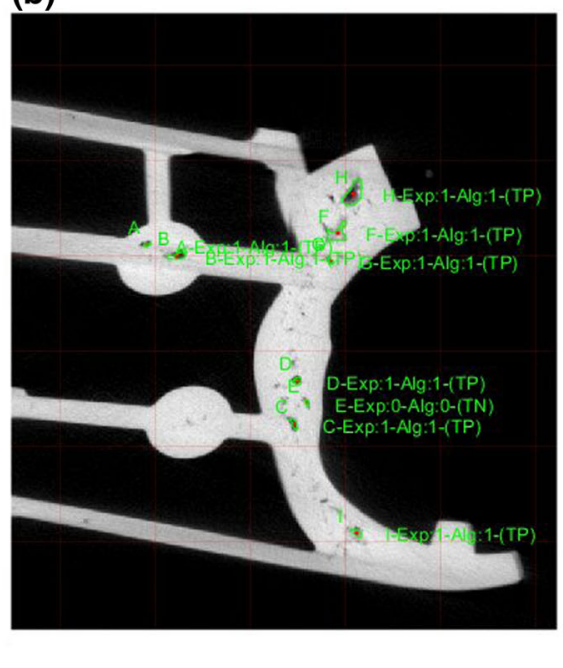

(c)

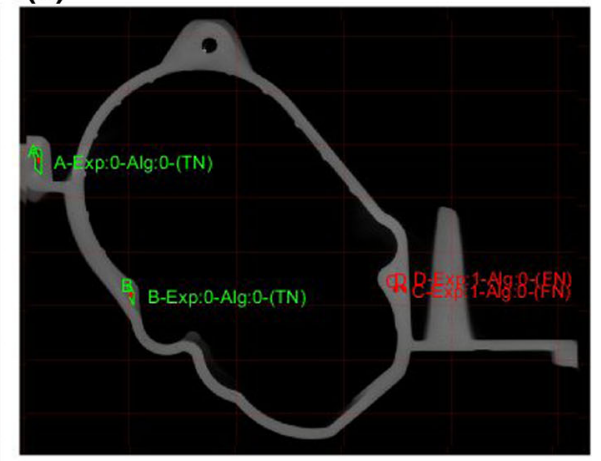

Fig. 10 Exemplary results: classification of defects—green—consistent with the expert, red—non-consistent with the expert (colour figure online) 
Fig. 11 Exemplary results: classification of

defects-green-consistent with the expert,

red-non-consistent with the expert (colour figure online) (a)

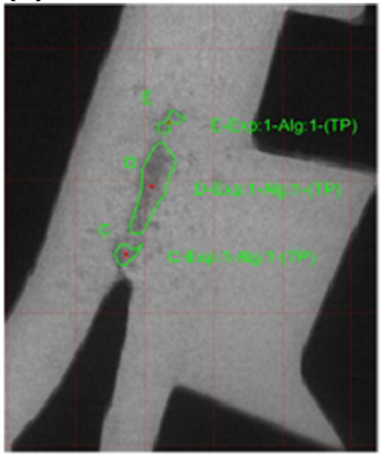

(d)

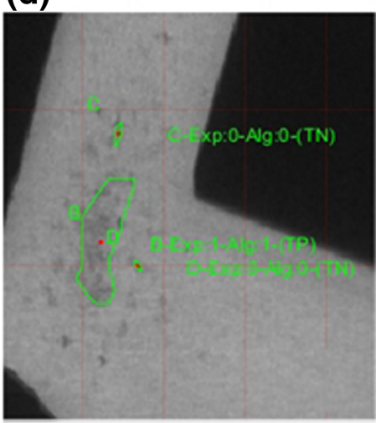

(g)

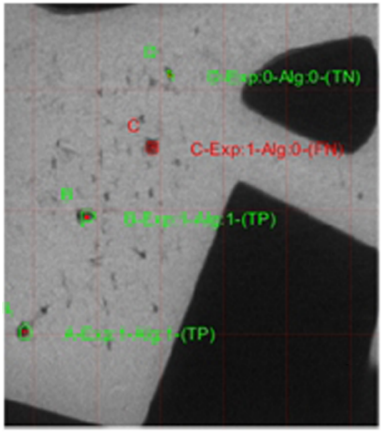

(j)

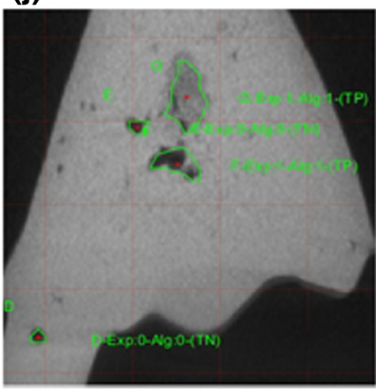

(b)

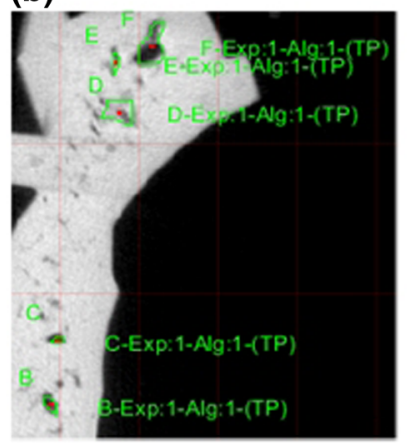

(e)

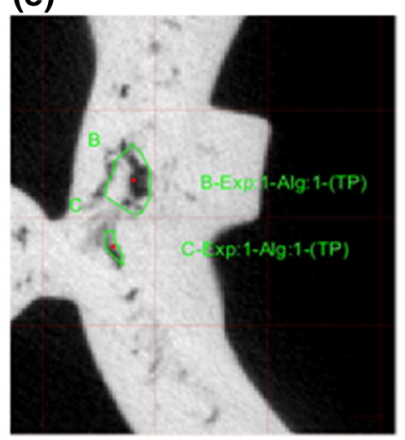

(h)

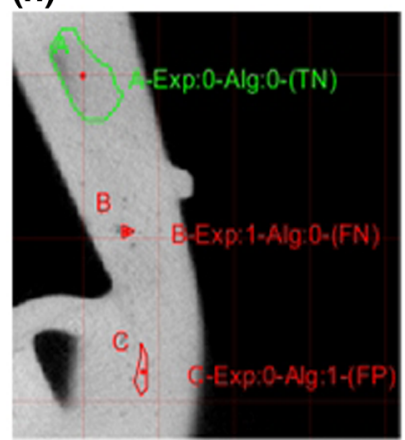

(k)

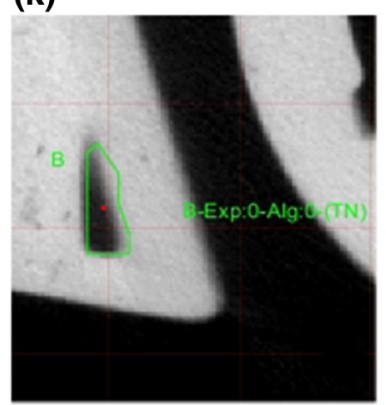

(c)

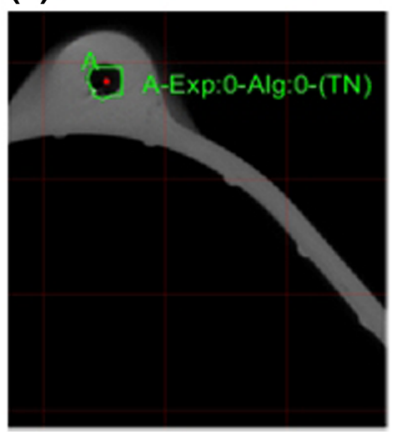

(f)

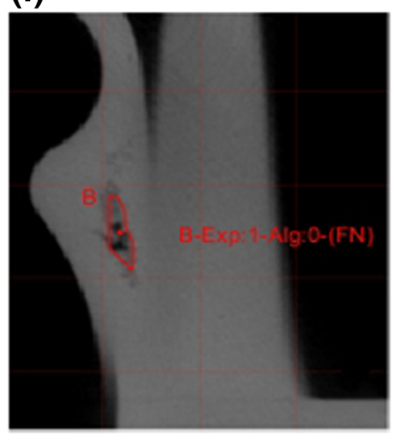

(i)

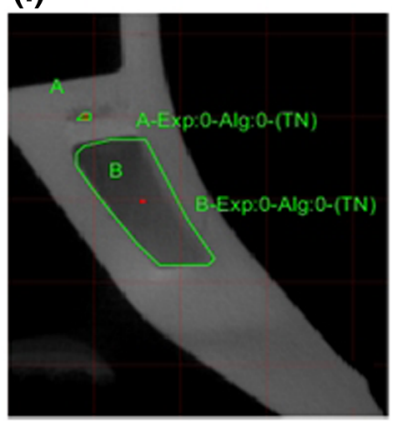

(I)

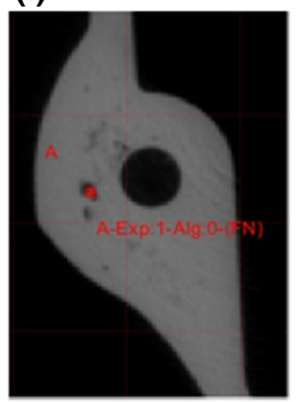

above -4.4$)$, which proves the correct and optimal choice of parameters. The average time of analysis of a single image with a graphical presentation of the results was less than $1 \mathrm{~s}$. The calculations were performed on the computer with an Ryzen 5 processor working at $3.8 \mathrm{GHz}$.

Since the method [19] provided slightly better results, its implementation was prepared on the basis of $[19,40]$ in order to verify its effectiveness and applicability in the examined set of $\mu$-CT images. Then, tests were carried out using images from publication [19] and from the $\mu$-CT image set prepared by the authors. Figure 12 a shows the results of the algorithm performance [19] in the x-Ray image from the set [19]correctly detected defect area. Figure $12 \mathrm{~b}$, c are examples of how the algorithm from [19] works in $\mu$-CT images. Figure $12 \mathrm{~b}$ shows examples of defect area detection throughout the image and Fig. 12c-in the element sections. As can 
(a)
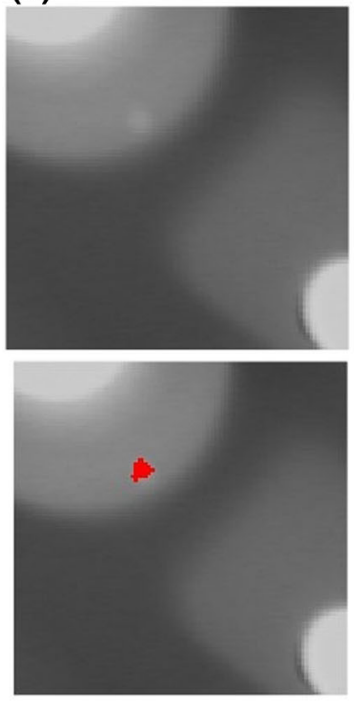

(b)

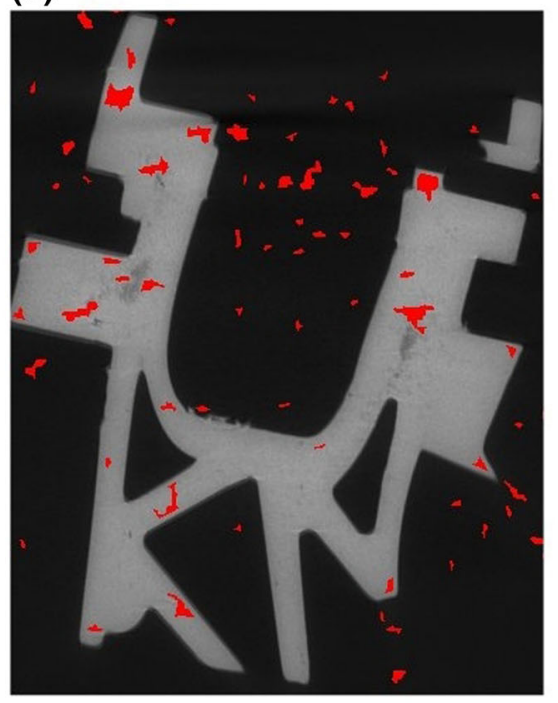

(c)
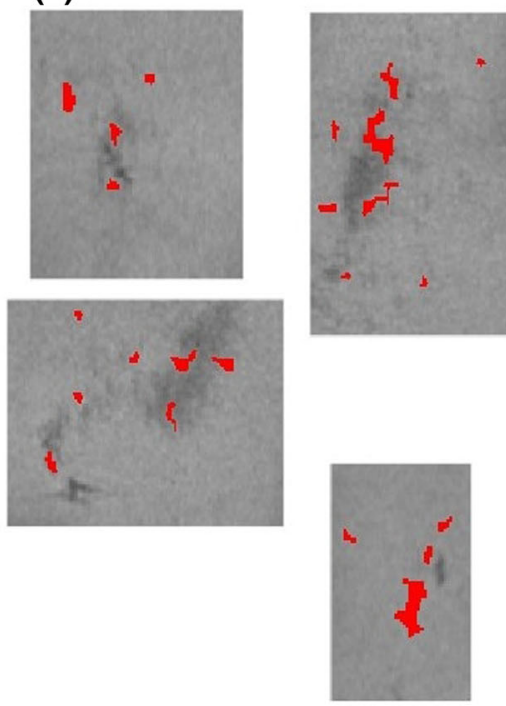

(d)
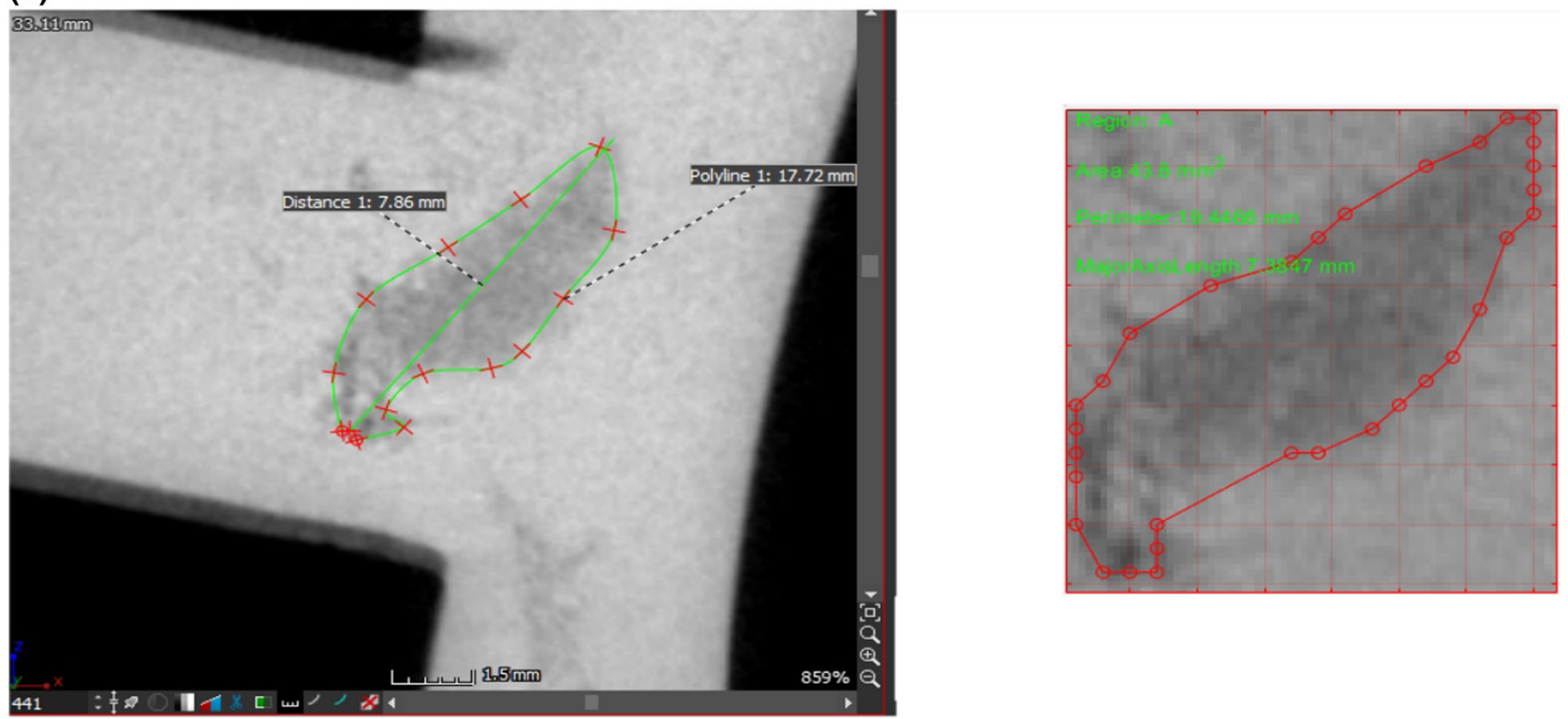

Fig. 12 Examples of how the method [19] works for x-ray images from [19] (a) and $\mu$-CT images (b, c). Manual measurement of the defect size in the myVGL application $\mathbf{d}$ left and using the algorithm $\mathbf{d}$ right

be seen in the attached images, the high efficiency of the method used for x-Ray images [19] does not translate into its effectiveness in $\mu$-CT images. The method does not correctly determine any of the defects, therefore its direct application in $\mu$-CT is impossible. In these cases, the method proposed by the authors achieves incomparably better results, which confirms its effectiveness in the case of $\mu$-CT images.

When analysing the obtained results, it can be observed that similar effectiveness of the algorithm was obtained in relation to the compared publications (despite different image types), which confirms that it is possible to achieve satisfac- tory results also for images obtained from $\mu$-CT. Analysis of this type of images additionally allows for localization of defects, which in standard methods may be invisible or hardly visible. Moreover in $\mu$-CT, if the defect is not detected in one layer (due to the automatic selection of the algorithm parameters), it is possible that it will be detected in the next layer, which globally increases the effectiveness of the entire solution when combining information from all layers. Figure 10 shows exemplary results of the developed algorithm for the images presented in Fig. 3. Examples Fig. 10a-c are defect areas indicated by the expert and by the developed algorithm. 
Relevant cases consistent with the expert classification (TP, TN) are marked in green, erroneous cases (FP, FN) - in red. In addition, there is information about the expert and algorithm classification.

It can be observed that the algorithm correctly locates defects of relatively large sizes. It incorrectly marks the one area $\mathrm{D}$, which the expert assessed as irrelevant from the point of view of the element quality-Fig. 10a. Further examples are images in Fig. 10b. Here, both the expert and the developed algorithm marked 9 areas as significant defects. The case in Fig. 10c is quite interesting. The test element has a completely different structure from the previous elements. Area A also appears here, which is the remnant of the technological hole in the previous layers but importantly, the algorithm reacts correctly and does not mark it as a defect. However, incorrect detection occurs in the case of areas C and $\mathrm{D}$, marked by the expert but not by the algorithm (color red). These areas are relatively dark and have a small size, which may affect the classifier behaviour. To sum up, these examples show that in most cases the algorithm reacts correctly only in the case of very small defects and its results are not always consistent with the expert's assessment.

Further examples are shown in Fig. 11, where the test areas are enlarged. As in Fig. 10, each case is marked as TP, TN, FP, $\mathrm{FN}$-classification consistent with the expert-green, nonconsistent-red. It can be observed in Fig. 11a, d, g, j how the algorithm easily locates almost all defect areas and correctly classifies them. It detects both very dark areas Fig. $11 \mathrm{j}$ and lighter ones Fig. 11a, b. Unselected areas do not meet the size criterion, so they are not subjected to classification. In the case of Fig. $11 \mathrm{~h}$ area B, the algorithm incorrectly classifies the area (FN). In the assessment of the casting quality, such a small area would not affect the test result. Similarly, in the case of Fig. 11h area C, despite the FP classification, the size of the area is not significant. An interesting case of correct classification of a technological hole $(\mathrm{TN})$ is presented in Fig. 11c, i, k. The algorithm, despite the large size of the areas, correctly classified them as Nondefects, which is consistent with the expert's assessment (TN). Figure 11f, 1 shows a defect classification error (B, A, respectively) despite the fairly good visibility of the defect during visual assessmentsuch cases indicate that the development and improvement of the algorithm may be the subject of further research.

Figure 111 is a case when a technologcial hole, due to its shape and structure, is not selected at all for further classification. This confirms that the algorithm block eliminating clear technological holes also works correctly. The most important feature of a defect, from the point of view of casting quality assessment, is its size. The examples in Figs. 10 and 11 show that the proposed method locates and classifies larger, most significant defects with high efficiency. The results of the algorithm effectiveness obtained in the test set for defects of various sizes are presented in Table 4 and Fig. 13.

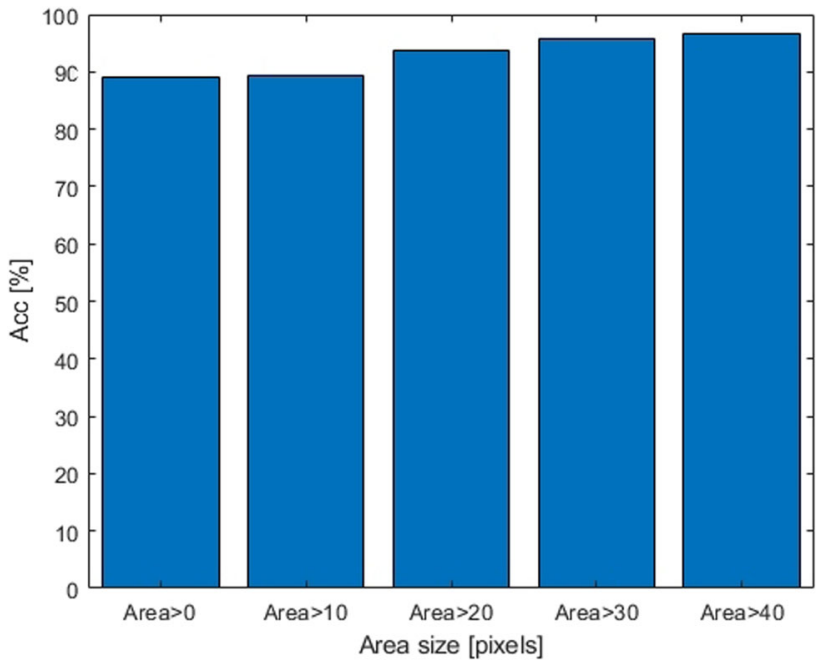

Fig. 13 Detection efficiency depending on the defect area

Based on the results obtained and the examples presented, it can be concluded that the proposed algorithm is very effective (Acc $=96.73 \%)$ in assessing larger, significant areas, and possible errors and lower effectiveness occur in the case of smaller, less significant defects.

In the process of generating features of areas, minimum surface area, perimeter and major axis length are determined for each defect. These values with known parameters of the microtomographic device allow for the quantitative assessment of the surface of each defect detected by the algorithm (in each tested layer) in $\mathrm{mm}^{2}$ or $\mathrm{mm}$. In the examined images, 1 image voxel corresponded to $75 \mu \mathrm{m}$ or $123 \mu \mathrm{m}$ (depending on the image). Based on these values and Eq. (8), the real sizes of the defect areas can be determined.

Area $_{\mathrm{R}}=$ Areapsc $_{\text {imgSc }} *$ voxelRatio
Perim $_{\mathrm{R}}=$ Perim $_{\mathrm{Psc}} * \operatorname{imgSc} *$ voxelRatio
Dist $_{\mathrm{R}}=$ Distpsc $_{\mathrm{P}} * \operatorname{imgSc} *$ voxelRatio

where Area $_{R}$, Perim $_{R}$, Dist $t_{R}$ real values in $\mathrm{mm}^{2}$ or $\mathrm{mm}$, Areapsc $_{\text {Ps }}$, Perim Psc, DistPsc values in pixels (in scaled image), imgSc scale at which the image is processed, voxelRatio ratio of voxel size to $1 \mathrm{~mm}$.

The results obtained can be used as input information for a decision system that will automatically assess the quality of the tested casting. An example of a practical, potential application, where the discussed algorithm could completely automate the process of casting testing, is publication [41]. Its authors presented a method for assessing the quality of elements based on micro-tomographic images analysed semi-automatically by the operator and specialized software. Full automation of this process can significantly facilitate and accelerate the assessment of casting quality, as well as allow 
Table 4 Detection efficiency depending on the defect area (89.01\% for all areas / 96.73 for the largest areas)

\begin{tabular}{llllllll}
\hline AreaP & TP & TN & FP & FN & Def. count & Non def. count & Acc $(\%)$ \\
\hline$>0$ & 375 & 638 & 60 & 65 & 440 & 698 & $\mathbf{8 9 . 0 1}$ \\
$>10$ & 204 & 88 & 21 & 14 & 218 & 109 & 89.29 \\
$>20$ & 107 & 58 & 7 & 4 & 111 & 65 & 93.75 \\
$>30$ & 73 & 37 & 4 & 1 & 74 & 41 & 96.65 \\
$>40$ & 61 & 28 & 2 & 1 & 62 & 30 & $\mathbf{9 6 . 7 3}$ \\
\hline
\end{tabular}

for the analysis of large data sets in an unsupervised manner and presentation of the results in the form of reports with a quantitative assessment of the tested elements. An example comparing the results obtained during manual measurement and determined by the algorithm is presented in Fig. 12d. The area perimeter and the largest area distance (determined manually and by using the proposed algorithm) reached the values from 17.72 to $19.44 \mathrm{~mm}$ and from 7.86 to $7.38 \mathrm{~mm}$, respectively, which gives a relative measurement error $9.7 \%$ (area perimeter) and $6.5 \%$ (area largest distance) compared to the manual measurement.

\subsection{Conclusions}

The paper proposes an original method of automatic localization and classification of defects in $\mu$-CT images based on image analysis methods and neural networks. Compared to typical solutions based on x-ray images, an innovative approach has been proposed that enables to analyse tomographic images of layers after reconstruction. Analysis of this type of images can allow for fully automatic acquisition of additional information (e.g. defect volume) or localization of defects hidden under the element fragments. At this stage of research, the proposed algorithm has obtained the effectiveness of correct detections similar to that of reference methods based on $x$-ray images. The maximum value of ACC is $89 \%$ and the mean value obtained in cross-validation $\mathrm{ACC}_{\mathrm{CVMean}}=86.6 \%$ (Table 3). When the largest and most important defects were searched for, the algorithm efficiency reached even $96.73 \%$ (Table 4).

The authors have also managed to optimize the network structure compared to the described solutions $[16,19,20]$ (especially in the hidden layer), which has a positive effect on the classifier speed. The expert during the manual evaluation analysed the previous and next layers in addition to the test layer, so if the algorithm is further improved to work in a similar way, it will provide more information and will be more effective. This can be particularly important for areas which are the remnants of technological holes in the neighbouring layers and are not actual defects. Proposed method allows the fast and fully automated analysis single or set of
$\mu$-CT images without user interaction and need for selection of image analysis parameters.

Open Access This article is licensed under a Creative Commons Attribution 4.0 International License, which permits use, sharing, adaptation, distribution and reproduction in any medium or format, as long as you give appropriate credit to the original author(s) and the source, provide a link to the Creative Commons licence, and indicate if changes were made. The images or other third party material in this article are included in the article's Creative Commons licence, unless indicated otherwise in a credit line to the material. If material is not included in the article's Creative Commons licence and your intended use is not permitted by statutory regulation or exceeds the permitted use, you will need to obtain permission directly from the copyright holder. To view a copy of this licence, visit http://creativecomm ons.org/licenses/by/4.0/.

\section{References}

1. Useche, J.N., Bermudez, S.: Conventional computed tomography and magnetic resonance in brain concussion. Neuroimaging Clin. N. Am. 28(1), 15-29 (2018)

2. Okumura, M., Usumoto, Y., Tsuji, A., Kudo, K., Ikeda, N.: Analysis of postmortem changes in internal organs and gases using computed tomography data. Leg. Med. 25(2017), 11-15 (2017)

3. Barak, M.M., Black, M.A.: A novel use of 3D printing model demonstrates the effects of deteriorated trabecular bone structure on bone stiffness and strength. J. Mech. Behav. Biomed. Mater. 78(2018), 455-464 (2018)

4. Okochi, T.: A nondestructive dendrochronological study on japanese wooden shinto art sculptures using micro-focus X-ray Computed Tomography (CT) Reviewing two methods for scanning objects of different sizes. Dendrochronologia 38, 1-10 (2016)

5. Moskała, A., Woźniak, K., Kluza, P, Bolechała, F., RzepeckaWoźniak,E., Kołodziej J, Latacz K.: Przydatność pośmiertnego badaniatomografii komputerowej $\mathrm{z}$ angiografią (PMCTA) w sądowo-lekarskiejdiagnostyce przypadków ran kłutych i ciétych. ARCH. MED. SA̧D.KRYMINOL., 2012, LXII, pp. 315-326 (2012)

6. Ratajczyk, E.: Rentgenowska tomografia komputerowa (CT) do zadań przemysłowych. Pomiary automatyka Robotyka 5(2012), 104-113 (2012)

7. Królikowski, M., Burbelko, A., Kwaśniewska-Królikowska, D.: Wykorzystanie tomografii komputerowej $\mathrm{w}$ defektoskopii odlewów z Żeliwa sferoidalnego. Arch. Foundry Eng. 14(4), 71-76 (2012)

8. Ewert U., Fuchs T.: Progress in digital industrial radiology Part II: computed tomography (CT). Badania Nieniszczące i Diagnostyka1-2 , 2017, pp. 7-14 (2017)

9. Le, V.-D., Saintier, N., Morel, F., Bellett, D., Osmond, P.: Investigation of the effect of porosity on the high cycle fatigue behaviour 
of cast Al-Si alloy by X-ray micro-tomography. Int. J. Fatigue 106, 24-37 (2018)

10. du Plessis, A., le Roux, S., Guelpa, A.: Comparison of medical and industrial X-ray computed tomography for non-destructive testing. Case Stud. Nondestruct. Test. Eval. 6(Part A), 17-25 (2016)

11. Wilczek, A., Długosz, P., Hebda, M.: Porosity characterization of aluminium castings by using particular non-destructive techniques. J. Nondestruct. Eval. 34, 26 (2015)

12. https://www.volumegraphics.com/en/products/vgstudio-max. html

13. https://imagej.net/

14. http://bruker-microct.com/products/ctan.htm

15. Świłło, S.J., Perzyk, M.: Surface casting defects inspection using video system and neural networks techniques. Arch Foundry Eng 13(4), 103-1069 (2013)

16. Dobrzański, L.A., Krupiński, M., Sokolowski, J.H.: Computer aided classification of flaws occurred during casting of aluminum. J. Mater. Process. Technol. 167(2-3), 456-462 (2005)

17. Dobrzański, L.A., Krupiński, M., Sokolowski, J.H.: Methodology of automatic quality control of aluminum castings. J. Achiev. Mater. Manuf. Eng. 20(1-2), 69-78 (2007)

18. https://www.astm.org/Standards/E155.htm

19. da Silva, R.R., Mery, D.: Accuracy estimation of detection of casting defects in x-ray images using some statistical techniques. In: PSIVT 2007: advances in image and video technology, pp. 639650 (2007)

20. Pizarro, L., Mery, D., Delpiano, R., Carrasco, M.: Robust automated multiple view inspection. Pattern Anal. Appl. 11(1), 21-32 (2008)

21. Arunmuthu, K., George Joseph, T., Saravanan: X-ray computed tomography based detection of casting defects in fatigue samples. In: 25th National Seminar and International Exhibition, Non Destrucitve Evaluation, November 26-28 (2015)

22. Nicoletto, G., Anzelotti, G., Konecna, R.: X-ray computed tomography vs. metallography for pore sizing and fatigue of cast Al-alloys. Procedia Eng. 2(1), 547-554 (2010)

23. Nicoletto, G., Konecna, R., Fintova, S.: Characterization of microshrinkage casting defects of $\mathrm{Al}-\mathrm{Si}$ alloys by $\mathrm{X}$-ray computed tomography and metallography. Int. J. Fatigue 41, 39-46 (2012)

24. Mery, D., Arteta, C.: Automatic defect recognition in X-ray testing using computer vision. In: 2017 IEEE Winter Conference on Application of Computer Vision (WACV), Santa Rosa, CA, USA (2017)

25. Osowski, S.: Sieci neuronowe do przetwarzania informacji (wyd.3), Oficyna Wydawnicza Politechniki Warszawskiej, p. 422 (2013)

26. Otsu, N.: A threshold selection method from gray-level histograms. IEEE Trans. Syst. Man Cybern. 9(1), 62-66 (1976)

27. Tadeusiewicz, R., Korohoda, P.: Komputerowa analiza i przetwarzanie obrazów, Wydawnictwo Fundacji Postępu Telekomunikacji, p. 280 (1997)

28. Marques, O.: Practical Image and Video Processing Using MATLAB, p. 704. Wiley, Hoboken (2011)

29. Gonzalez, R.C., Woods, R.E., Eddins Steven, L.: Digital Image Processing Using MATLAB 2e, p. 827. Gatesmark Publishing, London (2009)

30. Zhang, D., Han, J., Li, C., Wang, J., Li, X.: Detection of co-salient object by looking deep and wide. Int. J. Comput. Vis. 120, 215-232 (2016)

31. Gao, Z., Zhang, H., Dong, S., Sun, S., Wang, X., Yang, G., Wu, W., Li, S.: Salient object detection in the distributed cloud-edge intelligent network. IEEE Netw. 34, 216-224 (2020)

32. Xiao, B., Wang, K., Bi, X., Li, W., Han, J., Member, S.: 2D LBP an enhanced local binary features. IEEE Trans. Circuits Syst. Video Technol. 29(9), 2796-2808 (2019)
33. Zheng, Y., Jeon, B., Sun, L., Zhang, J., Zhang, H.: Student's tHidden Markow models for unsupervised learning using localised feature selection. IEEE Trans. Circuits Syst. Video Technol. 28, 1 (2017)

34. Mery, D., Filbert, D.: Classification of potential defects in automated inspection of aluminium castingusing statistical pattern recognition. In: 8th European Conference on Non-destructive Testing (ECNDT 2002), Barcelona, Spain (2002)

35. Sikora, R., Baniukiewicz, P., Chady, T., Lopato, P., Psuj, G.: Artigical neural networks and fuzzy logic in nondestructive evaluation. In: 18th World Conference on Nondestructive Testing, Durban (2012)

36. Zieliński, K.W., Strzelecki, M.: Komputerowa analiza obrazu biomedycznego, PWN, Warszawa, p. 367 (2001)

37. Osowski, S.: Metody i narzędzia eksploracji danych. Wydawnictwo BTC, Legionowo, p. 388 (2013)

38. Tadeusiewicz, R.: Sieci neuronowe. Akademicka Oficyna Wydawnicza, Warszawa, p. 299 (1993)

39. Tadeusiewicz, R.: Odkrywanie właściwości sieci neuronowych przy użyciu programów w języku C\#. Wydawnictwo Polskiej Akademii Umiejętności, Kraków, p. 426 (2007)

40. Domingo, M.: Computer Vision for X-Ray Testing, Imaging, Systems, Image Databases, and Algorithms, p. 347 (2015)

41. Le, V., Saintier, N., Morel, F., Bellett, D., Osmond, P.: Investigation of the effect of porosity on the high cycle fatigue behaviour of cast $\mathrm{Al}-\mathrm{Si}$ alloy by X-ray micro-tomography. Int. J. Fatigue 106, 24-37 (2017)

Publisher's Note Springer Nature remains neutral with regard to jurisdictional claims in published maps and institutional affiliations.

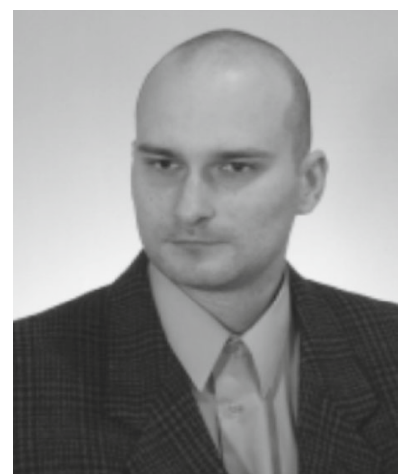

Mariusz Marzec is an assistant professor in Department of Biomedical Computer Systems at the Institute of Computer Science, Silesian University in Katowice. His scientific interests are computer analysis and processing of images, biomedical images, databases and programming languages. $\mathrm{He}$ is an author and co-author of scientific publications in analysis and processing of biomedical images and developing database systems.

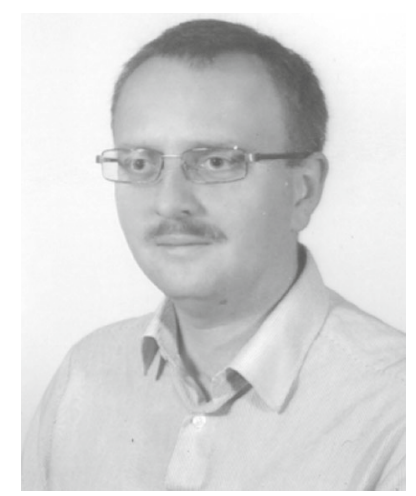

Piotr Duda is an assistant professor in Department of Biomedical Computer Systems at the Institute of Computer Science, Silesian University in Katowice. His scientific interests are biomedical engineering, tribology, microtomography and material engineering. He is an author and co-author of scientific publications in the field of tribology and the use of microtomography in pharmacy and biomedical engineering. 


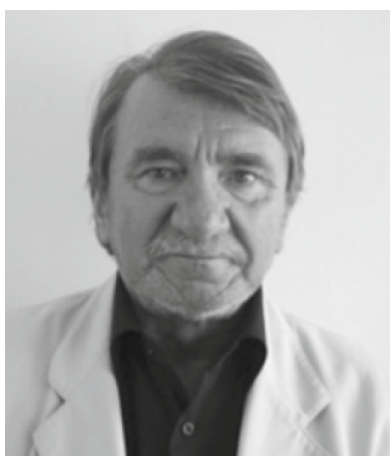

Zygmunt Wróbel is the Director of Institute of Computer Science of Silesian University in Katowice. His scientific interests are computer analysis and processing of biomedical images and signals, and applications of information technology in medicine and biotechnology. He is an author and coauthor of tens of scientific publications in analysis and processing of biomedical images and information technology. 